\title{
Asset Trading Volume in a Production Economy
}

\author{
Emilio Espino*and Thomas Hintermaier ${ }^{\dagger}$ \\ Department of Economics and Finance, \\ Institute for Advanced Studies (IHS), \\ Vienna, Austria
}

January 24, 2005

\begin{abstract}
This paper studies asset trading volume in production economies à la Brock [1982]. Agents are heterogeneous due to different labor productivities across firms. They may also have unequal initial levels of wealth but have identical preferences. We consider alternative dynamically complete market structures. Unlike its endowment version (e.g. the Lucas [1978] tree model with heterogeneous agents), this environment generates a nontrivial amount of trading in both short-lived and long-lived assets. We propose a relatively simple algorithm to compute equilibrium portfolios in production economies within a fairly general set of complete market structures. Also, we provide a new simple existence proof of recursive competitive equilibria with heterogeneous consumers.
\end{abstract}

JEL classification: C61, D50, E20, G11.

Keywords: Asset trading volume, complete markets, production economies.

\footnotetext{
${ }^{*}$ Corresponding author. Address: Department of Economics and Finance, Institute for Advanced Studies, Stumpergasse 56, 1060, Vienna, Austria. Tel.: +43-1-59 991 156; Fax: +43-1-59 991163. E-mail: espino@ihs.ac.at.

${ }^{\dagger}$ We would like to thank W. Brock, D. DeJong and, especially, H. Ennis for comments and suggestions. All the remaining errors are ours.
} 


\section{Introduction}

This paper studies asset trading volume in production economies with heterogenous agents and dynamically complete markets. The main source of heterogeneity is due to different labor productivities of agents across firms. They may also have unequal initial levels of wealth since agents are endowed with different technologies. These technologies, represented by neoclassical firms, produce the unique consumption good which is either consumed or invested. On the other hand, they have the same preferences over consumption bundles. The environment is then an extension of the celebrated Lucas [1978] tree model in the spirit of Brock's [1982] seminal contribution. ${ }^{1}$

The original Lucas tree model, one of the main workhorses in modern finance, is silent about trade volume. This is a direct consequence of studying a representative agent framework. However, even those versions of the model with heterogeneous agents have performed poorly to explain asset trading volume. In particular, Judd, Kubler and Schmedders [2003] (JKS [2003] from now on) have carefully studied this environment under assumptions that allow for fairly general patterns of heterogeneity across agents. They show that, after some initial rebalancing in asset and stock holdings, asset trading volume is restricted to a minimum. After the initial period, independently of the state of nature, agents choose a fixed equilibrium portfolio trading the same amount of short-lived assets and keeping fixed their stock holdings forever.

The empirical evidence rejects this prediction of fixed portfolios and shows a nontrivial volume of trading in assets and stocks that fluctuates according to the aggregate state of the economy. In fact, the finance literature has devoted a significant amount of attention to study these issues (see, for example, Brock and LeBaron [1996] and Lo and Wang [2000]). Very importantly, and as properly mentioned by JKS

\footnotetext{
${ }^{1}$ Different versions of this framework have been used to study asset pricing in economies with production. See Boldrin et al. [2001], Jermann [1998] and Lettau [2003] for a discussion of the main implications.
} 
[2003], models explaining this data might significantly improve our understanding of financial markets and provide valuable information about underlying preferences. The results in JKS [2003] necessarily call for going beyond the Lucas tree model with complete markets to fulfill this task. Thus, JKS [2003] conclude that “...other factors considered in the literature, such as life-cycle factors, asymmetric information, heterogeneous beliefs, and incompleteness of the asset market, play a significant role in generating trade volume".

Instead of relying on those frictions or market imperfections, we argue that a natural extension to consider first is the production economy proposed by Brock [1982], adapted to deal with heterogeneous agents. Our environment is then in line with the literature that has successfully explained both the evolution of real quantities and also important properties of asset prices (see footnote (1)). Within this framework, we consider different dynamically complete market structures to analyze equilibrium asset trading volume. We show that this environment can generate a nontrivial amount of trading in both short-lived and long-lived assets where equilibrium portfolios depend upon the aggregate state of the economy. The basic idea behind this result is the following. Consider first a pure exchange economy with individual endowments following stationary Markov processes. Suppose that there are $S$ states of nature and the corresponding $S$ Arrow securities are available to trade. Thus, both Welfare Theorems hold and competitive equilibrium allocations are Pareto optimal. With this Markovian structure, individual consumption and its corresponding excess demand will be vectors in $\mathbb{R}^{S}$ for any Pareto optimal allocation. With a full set of Arrow securities it is possible to span $\mathbb{R}^{S}$ itself and hence construct a fixed vector of asset holdings to attain any of these bundles. The same argument works for an economy with $S$ "trees" with linearly independent dividend processes: it is possible to attain any of these Pareto optimal bundles in $\mathbb{R}^{S}$ with a fixed portfolio of stock holdings.

Consider now an economy with capital. In this environment, agents can manip- 
ulate not only portfolios but also the stock of capital to transfer consumption across time and states of nature. To transfer resources either to or from some given state of nature next period, different levels of next-period's capital will make agents choose different portfolios. This is so because the stock of capital itself is used to transfer consumption between today and tomorrow. If the value of the marginal productivity of next-period's capital is high, an agent chooses to transfer more consumption to all the states next period using capital, hence trading less assets. On the other hand, if the value of the marginal productivity of next-period's capital is relatively low, he transfers less consumption through capital accumulation and purchases more assets paying next period.

The trading strategy of fixed portfolios is not optimal in equilibrium. The reason is the same that explains why it is not optimal in an endowment economy with nonstationary heterogeneity of agents. In this case, equilibrium excess demands will be in general time dependent if the degree of agents' heterogeneity changes through time. Thus, readjustment of asset portfolios would be needed. In an economy with capital accumulation, the time dependence of agents' heterogeneity is determined by the evolution of the distribution of capital across firms. This is the main force driving our results. In our environment, this changing heterogeneity across agents arises due to a natural physical friction in production economies with heterogenous consumers. There, machines are installed one period in advanced in a certain firm. Next period there is no chance to reallocate these machines after having observed individual productivities across firms. This implies that the marginal productivity of capital is not necessarily equalized ex-post across firms. We also assume that a crucial heterogeneity across agents is that their labor productivities differ across firms (limited labor substitutability). They can therefore have different equilibrium wages where this difference depends on the distribution of capital across firms. This naturally leads to heterogeneity among agents changing with the evolution of this distribution. 
In order to establish the theoretical reasons for the need of nontrivial trading volume, we obtain some results that might be of interest by their own. We propose an algorithm to compute equilibrium portfolios in production economies within a fairly general set of complete market structures. Also, as a by-product, we establish a relatively simple existence proof of recursive competitive equilibria with heterogeneous households.

The main contribution of our paper is methodological. The examples we provide are just to illustrate our main findings without any attempt to mimic specific features of the data. However, we do believe that quantitative experiments using carefully calibrated versions of our framework will be helpful in the study of more ambitious extensions.

The paper is organized as follows. In Section 2, we describe the economy and present our main theoretical results. In Section 3, we additionally restrict our economy to CRRA preferences to discuss some particular properties and compute some examples. Section 4 concludes. All proofs are in the Appendix.

\section{The Economy}

The economy is populated by $I$ (types of) infinitely-lived agents where $i \in \Upsilon=$ $\{1, \ldots, I\}$. Time is discrete and denoted by $t=1,2, \ldots$. Agents are endowed with one unit of time every period but, for simplicity, we assume that they do not value leisure. There is only one consumption good which can be either consumed or invested in a standard linear technology to produce new capital. ${ }^{2}$ There is aggregate uncertainty and $s_{t}$ represents the realization of this shock at date $t$. We assume that $\left\{s_{t}\right\}$ is a finite state first-order stationary Markov process. Transition probabilities are denoted by $\pi\left(s, s^{\prime}\right)$ and $s_{t}, s, s^{\prime} \in \mathbf{S}=\{1, \ldots, S\}$. Let $s^{t}=\left(s_{0}, \ldots, s_{t}\right)$ represent the partial history of aggregate shocks up to date $t$. These histories are observed by all the agents. The probability of $s^{t} \in S^{t+1}$ is constructed from $\pi$ in the standard way and $x\left(s^{t}\right)$ denotes

\footnotetext{
${ }^{2}$ It is straightforward to extend the analysis to include both nontrivial labor-leisure choices and also more general technologies to produce new capital goods. See Espino and Hintermaier [2005].
} 
the value of $x$ at the node $s^{t}$. The consumption set $\mathbf{C}$ is the space of bounded adapted non-negative consumption processes. That is,

$$
\mathbf{C}=\left\{\left\{c_{t}\right\}_{t=0}^{\infty} \mid c_{t}: S^{t+1} \rightarrow \mathbb{R}_{+}, \sup _{s^{t}} c\left(s^{t}\right)<\infty\right\}
$$

Preferences are identical across agents and represented by expected, time-separable, discounted utility. That is, if $c_{i} \in \mathbf{C}$ then:

$$
U\left(c_{i}\right)=\sum_{t=0}^{\infty} \sum_{s^{t} \in S^{t+1}} \beta^{t} \pi\left(s^{t}\right) u\left(c_{i}\left(s^{t}\right)\right),
$$

where $\beta \in(0,1)$ and $u: \mathbb{R}_{+} \rightarrow \mathbb{R}_{+}$is strictly increasing, strictly concave and continuously differentiable. Additionally, we assume that $u^{\prime}(0)=+\infty$ to rule out corner solutions. The assumption of identical utility functions is irrelevant for our results in this section. Additional heterogeneity in this dimension could be easily included, adding in general another potential source for trade. ${ }^{3}$

There are $I$ technologies available in the economy to produce the consumption good. Let $K_{i}\left(s^{t}\right) \geq 0$ denote the stock of capital chosen at the node $s^{t}$ and available in period $t+1$ to produce with technology $i$. Let $B_{i}(s) F\left(K_{i}, L_{i}\right)$ represent technology $i$, where $B_{i}: S \rightarrow \mathbb{R}_{++}$and $F: \mathbb{R}_{+}^{2} \rightarrow \mathbb{R}_{+}$is concave, strictly increasing, continuously differentiable and satisfies for all $L_{i}>0$ : (a) $\partial F\left(0, L_{i}\right) / \partial K_{i}=\infty$ and (b) $\lim _{K_{i} \rightarrow \infty} \partial F\left(K_{i}, L_{i}\right) / \partial K_{i}=0$. Condition (a) rules out corner solutions. More importantly, condition (b) guaranties that there exists some $\bar{K}$ such that $0 \leq K_{i}\left(s^{t}\right) \leq \bar{K}$ for all $s^{t}$ and all $i$ since consumption must be non-negative. ${ }^{4}$ Without loss of generality, we can restrict ourselves to $\left(K_{1}\left(s^{t}\right), \ldots, K_{I}\left(s^{t}\right)\right) \in X \equiv \bar{K}^{I}$ for all $s^{t}$. We denote $K_{i}=\left(K_{i}\left(s^{t}\right)_{s^{t}}\right), K=\left(K_{1}, \ldots, K_{I}\right)$ where $K^{0}=\left(K_{1}^{0}, \ldots, K_{I}^{0}\right) \in X$ is the initial stock of capital which is assumed to be strictly positive. Note that, for each $i, L_{i}\left(s^{t}\right)=1$ for all $s^{t}$ and denote $f\left(K_{i}\left(s^{t-1}\right)\right)=F\left(K_{i}\left(s^{t-1}\right), 1\right)$. We assume that $B_{i} \neq B_{h}$ for some $i, h$ to guaranty heterogeneity across firms.

\footnotetext{
${ }^{3}$ Differences in discount factor might be more misleading. In that case, it can be shown that the limiting distribution of consumption will concentrate full mass in the relatively patient agent (see Espino [2005]).

${ }^{4}$ See Brock [1982, p. 23].
} 
To study asset trading volume, we need to compute equilibrium portfolios. But solving the problem directly is difficult. In turn, we follow an indirect, well-known, strategy proceeding as follows. We first characterize the set of Pareto optimal allocations. Then, we use the fact that both Welfare Theorems hold since we will analyze competitive equilibria with alternative complete market structures. In particular, we want to apply the Second Welfare Theorem characterizing the particular Pareto optimal allocation that be decentralized as a competitive equilibrium with zero initial transfers for each individual. This will then establish the existence of a competitive equilibrium and it will allow us to study the ability of this framework to generate asset trading volume.

\section{Planner's Problem}

Under our concavity assumptions on both utility and production functions, the set of Pareto optimal allocations can be parametrized by welfare weights. Suppose then that the welfare weight assigned by the planner to agent $i$ is denoted $\alpha_{i}$. Given a vector of welfare weights $\alpha=\left(\alpha_{i}\right)_{i \in \Upsilon}$, the planner's problem is given by:

$$
V\left(s_{0}, K_{0} ; \alpha\right)=\max _{(c, K) \geq 0} \sum_{i \in \Upsilon} \alpha_{i}\left\{\sum_{t=0}^{\infty} \sum_{s^{t} \in S^{t+1}} \beta^{t} \pi\left(s^{t}\right) u\left(c_{i}\left(s^{t}\right)\right)\right\},
$$

subject to

$$
\begin{aligned}
\sum_{i \in \Upsilon} c_{i}\left(s^{t}\right)+\sum_{i \in \Upsilon}\left[K_{i}\left(s^{t}\right)-(1-\delta) K_{i}\left(s^{t-1}\right)\right] & =\sum_{i \in \Upsilon} B_{i}\left(s_{t}\right) f\left(K_{i}\left(s^{t-1}\right)\right) \quad \text { for all } s^{t} \\
K\left(s^{t}\right) & \in X \text { for all } s^{t} \\
\text { and } \quad K^{0} & \in X \text { given. }
\end{aligned}
$$

It is a standard exercise to establish that this problem has a recursive formulation (see Stokey, Lucas and Prescott [1989]). The value function $V: \mathbf{S} \times X \times \mathbb{R}_{+}^{I} \rightarrow \mathbb{R}$ solves the following functional equation:

$$
V(s, K ; \alpha)=\max _{(c, K) \geq 0}\left\{\sum_{i \in \Upsilon} \alpha_{i} u\left(c_{i}\right)+\beta \sum_{s^{\prime}} \pi\left(s, s^{\prime}\right) V\left(s^{\prime}, K^{\prime} ; \alpha\right)\right\}
$$


subject to

$$
\begin{aligned}
\sum_{i \in \Upsilon} c_{i}+\sum_{i \in \Upsilon}\left[K_{i}^{\prime}-(1-\delta) K_{i}\right] & =\sum_{i \in \Upsilon} B_{i}(s) f\left(K_{i}\right), \\
K^{\prime} & \in X .
\end{aligned}
$$

Moreover, it can also be shown that $V$ is strictly increasing, strictly concave in $K$ and continuously differentiable in the interior of $X$. The solution to the problem $(\mathrm{RPP})$ is a set of continuous policy functions $\left(c_{i}(s, K ; \alpha), K_{i}^{\prime}(s, K ; \alpha)\right)_{i \in \Upsilon}$ fully characterizing the set of Pareto optimal allocations.

It is also well-known that both Welfare Theorems hold in this framework. As already mentioned, we are particularly interested in applying the Second Welfare Theorem to decentralize a Pareto optimal allocation as a competitive equilibrium without transfers. Before doing so, we briefly consider an Arrow-Debreu economy to get more intuition about our main results.

\section{An Arrow-Debreu Framework}

We assume that agent $i$ is endowed with technology $i$. Also, their endowments of time must be used in the technology with their names. This means that they are not productive in technologies with other names. This is an extreme assumption of limited labor substitutability made mainly to simplify the analysis. As the examples below illustrate, this does not necessarily mean that agents are ex-ante heterogeneous. The crucial aspect here is that agents are ex-post heterogeneous and this heterogeneity changes through time according to the evolution of the distribution of capital across firms. It is important to mention, however, that these assumptions are sufficient but not necessary for the results. In fact and as discussed in more detail below, it is possible to consider both more general initial distributions of wealth and also more general labor productivities across firms.

Suppose that all trade is done at date 0. That is, agents can sign (and fully enforce) contingent contracts for each $s^{t}$ at date 0 . Let $P\left(s^{t}\right)$ be the price of the consumption good to be delivered at the node $s^{t}$. We normalize $P\left(s_{0}\right)=1$. Assume 
that each agent runs his own firm and that, without loss of generality, they do not trade shares for these firms. Below we consider the more general case.

Definition 1 An Arrow-Debreu Competitive Equilibrium (ADCE) is an allocation $(\mathbf{c}, \mathbf{K})$ and a price system $\mathbf{P}$ such that

(ADCE 1) Given $\mathbf{P},\left(\mathbf{c}_{i}, \mathbf{K}_{i}\right)$ solves agent i's problem

$$
\max _{\left(\mathbf{c}_{i}, \mathbf{K}_{i}\right) \geq \mathbf{0}} \sum_{t} \sum_{s^{t}} \beta^{t} \pi\left(s^{t}\right) u\left(c_{i}\left(s^{t}\right)\right)
$$

subject to

$$
\sum_{t} \sum_{s^{t}} P\left(s^{t}\right) c_{i}\left(s^{t}\right)=\sum_{t} \sum_{s^{t}} P\left(s^{t}\right)\left[B_{i}\left(s_{t}\right) f\left(K_{i}\left(s^{t-1}\right)\right)+(1-\delta) K_{i}\left(s^{t-1}\right)-K_{i}\left(s^{t}\right)\right]
$$

where $\left(s_{0}, K_{0}\right)$ are given.

(ADCE 2) For all $s^{t}$ :

$$
\sum_{i \in \Upsilon}\left(c_{i}\left(s^{t}\right)+K_{i}\left(s^{t}\right)-(1-\delta) K_{i}\left(s^{t-1}\right)\right)=\sum_{i \in \Upsilon} B_{i}\left(s_{t}\right) f\left(K_{i}\left(s^{t-1}\right)\right) .
$$

It is well-known how to decentralize any Pareto optimal allocation (parametrized by the vector of welfare weights $\alpha)$ as an ADCE with transfers. ${ }^{5}$ Let $(\mathbf{c}(\alpha), \mathbf{K}(\alpha))$ be the solution to the planner's problem (PP) corresponding to welfare weights $\alpha$. Let $P\left(s^{t} ; \alpha\right)$ be the implicit price system obtained from the (normalized) Lagrange multipliers corresponding to the resource constraint at $s^{t}$ for the planner's problem $(\mathrm{PP})$.

Define the value of consumption for agent $i$ by:

$$
V_{C}^{i}\left(s_{0}, K_{0} ; \alpha\right)=c_{i}\left(s_{0}, K_{0} ; \alpha\right)+\sum_{t \geq 1} \sum_{s^{t}} P\left(s^{t} ; \alpha\right) c_{i}\left(s^{t} ; \alpha\right) .
$$

In the same way, define the value of net total wealth for agent $i$ by:

$$
\begin{aligned}
V_{W}^{i}(s, K ; \alpha)= & B_{i}\left(s_{0}\right) f\left(K_{i}^{0}\right)+(1-\delta) K_{i}^{0}-K_{i}\left(s_{0} ; \alpha\right) \\
& +\sum_{t \geq 1} \sum_{s^{t}} P\left(s^{t} ; \alpha\right)\left[B_{i}\left(s_{t}\right) f\left(K_{i}\left(s^{t-1} ; \alpha\right)\right)\right. \\
& \left.+(1-\delta) K_{i}\left(s^{t-1} ; \alpha\right)-K_{i}\left(s^{t} ; \alpha\right)\right] .
\end{aligned}
$$

\footnotetext{
${ }^{5}$ Moreover, it can be shown that in fact the equilibrium price system has inner product representation in this framework. See Stokey, Lucas and Prescott [1989, Chapter 15].
} 
The initial transfer for agent $i$ needed to decentralize a Pareto optimal allocation (parametrized with $\alpha$ ) as a ADCE with transfers is then given by:

$$
A_{i}\left(s_{0}, K_{0} ; \alpha\right)=V_{C}^{i}\left(s_{0}, K_{0} ; \alpha\right)-V_{W}^{i}\left(s_{0}, K_{0} ; \alpha\right)
$$

This means that, given $\left(s_{0}, K_{0} ; \alpha\right)$, there exists a unique distribution of net transfers determined by (3). Consider (3) evaluated at $\left(s_{t}, K\left(s^{t-1}\right)\right)$. That amount would represent the implicit net "asset position" of every agent when node $s^{t}$ is reached and the implied distribution of capital is given by $K\left(s^{t-1}\right)$. In fact, one can follow Negishi's [1960] approach and show that there exists a vector $\alpha_{0}=\alpha\left(s_{0}, K_{0}\right)$ such that $A_{i}\left(s_{0}, K_{0} ; \alpha_{0}\right)=0$ for all $i$. This establishes the existence of an ADCE as defined above. Alternatively, we show that it is simpler if we consider the equivalent formulation with sequential trading on spot markets and its corresponding recursive version. There, the functions $A_{i}^{\prime}$ s will play a crucial role for both constructing equilibrium portfolios and establishing the existence of competitive equilibria using the Negishi approach. Moreover, the following framework with sequential markets will allow us to study asset trading in its natural environment.

\subsection{Sequential Trading and Recursive Competitive Equilibrium}

Here we will consider two different decentralization structures with sequential trading and complete markets to study asset trading volume. We will not discuss the well-known equivalence results between the allocations and prices corresponding to the following market structures with sequential trading and the previously discussed ADCE allocations and prices. ${ }^{6}$

To study different complete market structures, we first present the general framework regarding trading opportunities. Every period $t$ and after having observed $s^{t}$, agents meet in spot markets to trade the consumption good and different assets. The possibility of trading $I$ different firm shares implies that there are $I$ long-lived assets available. Let $\theta_{i j}\left(s^{t}\right)$ be the number of firm $j$ 's shares chosen by agent $i$ at $s^{t}$. There

\footnotetext{
${ }^{6}$ See Ljungqvist and Sargent [2004, Chapter 8].
} 
is one outstanding share for each firm and then $\sum_{i} \theta_{i j}\left(s^{t}\right)=1$ for all $s^{t}$ and $j{ }^{7}$ We do not impose short selling constraints however. ${ }^{8}$

Our assumption about the initial distribution of wealth implies that for each $i$ :

$$
\theta_{i j}\left(s_{-1}\right)=\left\{\begin{array}{lr}
1 & \text { if } i=j \\
0 & \text { otherwise }
\end{array}\right.
$$

As before, agents must work in firms of their type. The relevance of this assumption and how to relax it is discussed below. Let $p_{j}\left(s^{t}\right)$ be the ex-dividend price of one share for firm $j$ at the node $s^{t}$. Let $w_{j}\left(s^{t}\right)$ be the wage paid in firm $j$ per unit of labor.

Agents can also trade a full set of Arrow securities with zero net supply. The Arrow security $s^{\prime}$ traded at $s^{t}$ pays one unit of consumption next period if $s_{t+1}=s^{\prime}$ and 0 otherwise. Let $q\left(s^{t}\right)\left(s^{\prime}\right)$ be the price of this security at $s^{t}$. Denote $a_{i}\left(s^{t}, s^{\prime}\right)$ the holdings of this security. We restrict agents to bounded trading strategies to rule out Ponzi schemes. These (implicit) bounds are assumed to be sufficiently large such that they do not bind in equilibrium. All prices are in units of the $s^{t}$-consumption good.

In this framework with complete markets it is immaterial who runs the firm. ${ }^{9}$ The firm's problem is thus to maximize its value. Note that if the firm is not traded in equilibrium, the problem reduces to an economy where agent of type $i$ runs his own firm. Firm $j$ 's problem at $s^{t}$ (with a stock of capital $K_{j}\left(s^{t-1}\right)$ ) is given by:

$$
D_{j}\left(s^{t}\right)=\max _{K_{j} \geq 0}\left\{d_{j}\left(s^{t}\right)+\sum_{s^{\prime}} q\left(s^{t}\right)\left(s^{\prime}\right) D_{j}\left(s^{t}, s^{\prime}\right)\right\},
$$

subject to

$$
d_{j}\left(s^{t}\right)=B_{j}\left(s_{t}\right) F\left(K_{j}\left(s^{t-1}\right), L_{j}\left(s^{t}\right)\right)+(1-\delta) K_{j}\left(s^{t-1}\right)-K_{j}\left(s^{t}\right)-w_{j}\left(s^{t}\right) L_{j}\left(s^{t}\right),
$$

for all $s^{t}$. Here, $D_{j}\left(s^{t}\right)$ is firm $j$ 's value at $s^{t}$.

\footnotetext{
${ }^{7}$ This assumption does not affect the results since the Modigliani-Miller theorem holds in this framework and therefore firms' financial policies do not affect allocations and prices.

${ }^{8}$ This last assumption is not crucial and it is frequently used in the literature (see, for example, Constantinides and Duffie [1996] and JKS [2003]). Brock [1982], however, assumes away short sales.

${ }^{9}$ Note that there is no conflict of interest here since allocations will be Pareto optimal. Hence, marginal rates of substitution are equalized across agents of different type.
} 
From the consumer side, given a price system $(\mathbf{p}, \mathbf{q}, \mathbf{w})$ agent $i^{\prime}$ s problem is given by:

$$
\max _{\left(c_{i}, a_{i}, \theta_{i}\right)} \sum_{t} \sum_{s^{t}} \beta^{t} \pi\left(s^{t}\right) u\left(c_{i}\left(s^{t}\right)\right)
$$

subject to

$$
\begin{gathered}
c_{i}\left(s^{t}\right)+\sum_{j} p_{j}\left(s^{t}\right) \theta_{i j}\left(s^{t}\right)+\sum_{s^{\prime}} q\left(s^{t}\right)\left(s^{\prime}\right) a_{i}\left(s^{t}, s^{\prime}\right) \\
=w_{i}\left(s^{t}\right)+a_{i}\left(s^{t-1}, s_{t}\right)+\sum_{j}\left[p_{j}\left(s^{t}\right)+d_{j}\left(s^{t}\right)\right] \theta_{i j}\left(s^{t-1}\right),
\end{gathered}
$$

where $c_{i} \geq 0$ and $\left(a_{i}, \theta_{i}\right)$ are bounded.

Definition 2 A Competitive Equilibrium with Sequential Trading (STCE) is a price system $(\widehat{\mathbf{p}}, \widehat{\mathbf{q}}, \widehat{\mathbf{w}})$ and an allocation $\left\{\left(\widehat{c}_{i}, \widehat{\theta}_{i}, \widehat{a}_{i}\right)_{i},\left(\widehat{K}_{j}\right)_{j}\right\}$ such that:

(STCE 1) Given $(\widehat{\mathbf{p}}, \widehat{\mathbf{q}}, \widehat{\mathbf{w}}),\left(\widehat{c}_{i}, \widehat{\theta}_{i}, \widehat{a}_{i}\right)$ solves agent $i$ 's problem for each $i$.

(STCE 2) Given $(\widehat{\mathbf{p}}, \widehat{\mathbf{q}}, \widehat{\mathbf{w}}),\left(\widehat{K}_{j}\right)$ solves firm j's problem for each $j$.

(STCE 3) All markets clear: for all $s^{t}$

$$
\begin{aligned}
\sum_{i \in \Upsilon} c_{i}\left(s^{t}\right)+\sum_{i \in \Upsilon}\left[K_{i}\left(s^{t}\right)-(1-\delta) K_{i}\left(s^{t-1}\right)\right] & =\sum_{i \in \Upsilon} B_{i}\left(s_{t}\right) f\left(K_{i}\left(s^{t-1}\right)\right), \\
\sum_{i} \widehat{a}_{i}\left(s^{t}, s^{\prime}\right) & =0 \text { for all } s^{\prime}, \\
\sum_{i} \widehat{\theta}_{i j}\left(s^{t}\right) & =1 \text { for all } j .
\end{aligned}
$$

This framework is particularly relevant because it allows to price any security. For example, consider a short-lived security $n$ with zero net supply and payoffs at $t$ given by $h_{n}\left(s_{t}\right)$. If we denote $q_{n}\left(s^{t}\right)$ the price of this security at $s^{t}$, then it follows by non-arbitrage arguments that:

$$
q_{n}\left(s^{t}\right)=\sum_{s^{\prime}} q\left(s^{t}\right)\left(s^{\prime}\right) h_{n}\left(s^{\prime}\right)
$$

The Markovian structure of our problem assures that, given a STCE, there exists an equivalent Recursive Competitive Equilibrium (RCE). ${ }^{10}$ Consider the set of state

\footnotetext{
${ }^{10}$ Here we purposely avoid the concept of Markov Equilibrium. Instead, we follow the literature pioneered by Mehra and Prescott [1980] and its related concept of RCE. See also Ljungqvist and Sargent [2004, Chapter 12].
} 
variables. At the consumer level, these are described by $\left(a_{i}, \theta_{i}\right)$, individual asset and share holdings, respectively. At the firm level, $k_{j}$ describes firm $j$ 's stock of capital. Let $A, \Theta$ and $K$ describe the distribution of assets, share holdings and capital, respectively. Therefore, at the aggregate level the set of aggregate state variables is fully described by $(s, \Theta, A, K)$. The price system is given by $\mathbf{p}, \mathbf{Q}, \mathbf{w}$ : $\mathbf{S} \times \mathbb{R}_{+}^{I} \times \mathbb{R}_{+}^{I} \times \mathbb{R}_{+}^{I} \rightarrow \mathbb{R}_{++}$representing prices for shares, Arrow securities and wages, respectively.

Definition $3 A R C E$ is a set of value functions for the individuals $\left(V_{i}\right)_{i \in \Upsilon}$, value functions for the firms $\left(D_{j}\right)_{j \in \Upsilon}$, a set of policy functions for the individuals $\left(c_{i}, a_{i}^{\prime}, \theta_{i}^{\prime}\right)_{i \in \Upsilon}$, policy functions for the firms $\left(k_{j}^{\prime}\right)_{j \in \Upsilon}$, a set of prices $(\mathbf{p}, \mathbf{Q}, \mathbf{w})$ and laws of motion for the aggregate state variables $A^{\prime}=G(s, A, \Theta, K), \Theta^{\prime}=J(s, A, \Theta, K)$ and $K^{\prime}=H(s, A, \Theta, K)$, such that:

$(\boldsymbol{R C E} \mathbf{1})$ Given $(\mathbf{p}, \mathbf{Q}, \mathbf{w})$, for each agent $i\left(c_{i}, a_{i}^{\prime}, \theta_{i}^{\prime}\right)$ are the corresponding policy functions and $\left(V_{i}, c_{i}, a_{i}^{\prime}, \theta_{i}^{\prime}\right)$ solves:

$$
V_{i}\left(a_{i}, \theta_{i}, s, A, \Theta, K\right)=\sup _{c, a^{\prime}, \theta^{\prime}}\left\{u(c)+\beta E\left[V_{i}\left(a_{i}^{\prime}, \theta_{i}^{\prime}, s^{\prime}, A^{\prime}, \Theta^{\prime}, K^{\prime}\right) \| s\right]\right\}
$$

subject to

$$
\begin{aligned}
& c_{i}+\sum_{j} p_{j}(s, A, \Theta, K) \theta_{i j}^{\prime}+\sum_{s^{\prime}} Q(s, A, \Theta, K)\left(s^{\prime}\right) a_{i}^{\prime}\left(s^{\prime}\right), \\
= & w_{i}(s, A, \Theta, K)+a_{i}+\sum_{j}\left[p_{j}(s, A, \Theta, K)+d_{j}(s, A, \Theta, K)\right] \theta_{i j},
\end{aligned}
$$

where $A^{\prime}=G(s, A, \Theta, K), \Theta^{\prime}=J(s, A, \Theta, K)$ and $K^{\prime}=H(s, A, \Theta, K)$.

$(\boldsymbol{R C E} 2)$ Given $(\mathbf{p}, \mathbf{Q}, \mathbf{w}), D_{j}$ is the recursive version of (4) and $\left(k_{j}^{\prime}\right)$ solves the firm j's problem, where dividends are given by:

$$
d_{j}\left(s, k_{j}, A, \Theta, K\right)=B_{j}(s) f\left(k_{j}\right)+(1-\delta) k_{j}-k_{j}^{\prime}\left(s, k_{j}, A, \Theta, K\right)-w_{j}(s, A, \Theta, K) .
$$

(RCE 3) All markets clear.

$$
\sum_{i \in \Upsilon} c_{i}\left(a_{i}, \theta_{i}, s, A, \Theta, K\right)+\sum_{j \in \Upsilon}\left(k_{j}^{\prime}\left(s, k_{j}, A, \Theta, K\right)-(1-\delta) k_{j}\right)=\sum_{j \in \Upsilon} B_{j}(s) f\left(k_{j}\right),
$$




$$
\begin{aligned}
& \sum_{i \in \Upsilon} a_{i}^{\prime}\left(a_{i}, \theta_{i}, s, A, \Theta, K\right)\left(s^{\prime}\right)=0 \quad \text { for all } s^{\prime}, \\
& \sum_{i \in \Upsilon} \theta_{i}^{j \prime}\left(a_{i}, \theta_{i}, s, A, \Theta, K\right)=1 \quad \text { for all } j .
\end{aligned}
$$

(RCE 4) Consistency. For all $(s, A, \Theta, K)$, each $i$ and each $j$ :

$$
\begin{aligned}
A_{i}^{\prime} & =G_{i}(s, A, \Theta, K)=a_{i}^{\prime}\left(A_{i}, \Theta_{i}, s, A, \Theta, K\right), \\
\Theta_{i}^{\prime} & =J_{i}(s, A, \Theta, K)=\theta_{i}^{\prime}\left(A_{i}, \Theta_{i}, s, A, \Theta, K\right), \\
K_{j}^{\prime} & =H_{j}(s, A, \Theta, K)=k_{j}^{\prime}\left(s, K_{j}, A, \Theta, K\right) .
\end{aligned}
$$

The following result will allow us to compute recursively the present discounted value of different streams. Given $\alpha$, consider the corresponding Pareto optimal allocation to define the stochastic discount factor by:

$$
Q(s, K ; \alpha)\left(s^{\prime}\right)=\beta \pi\left(s, s^{\prime}\right) \frac{u^{\prime}\left(c_{1}\left(s^{\prime}, K^{\prime}(s, K ; \alpha) ; \alpha\right)\right)}{u^{\prime}\left(c_{1}(s, K ; \alpha)\right)} .
$$

As we will see, agent 1 has been chosen without loss of generality. Let $\mathbf{C}_{\mathbf{B}}\left(\mathbf{S} \times \mathbb{R}_{+}^{I} \times \mathbb{R}_{+}^{I}\right)$ be the set of continuous and bounded functions mapping $\mathbf{S} \times \mathbb{R}_{+}^{I} \times \mathbb{R}_{+}^{I}$ into the real numbers. For any continuous function $r: \mathbf{S} \times \mathbb{R}_{+}^{I} \times \mathbb{R}_{+}^{I} \rightarrow \mathbb{R}$, consider the operator $T$ defined by:

$$
(T R)(s, K ; \alpha)=r(s, K ; \alpha)+\sum_{s^{\prime}} Q(s, K ; \alpha)\left(s^{\prime}\right) R\left(s^{\prime}, K^{\prime}(s, K ; \alpha) ; \alpha\right) .
$$

Lemma 4 Suppose that $u^{\prime}\left(c_{1}(s, K ; \alpha)\right) r(s, K ; \alpha)$ is uniformly bounded and continuous for all $(s, K ; \alpha)$ ( that is, $\left(u^{\prime} \circ c_{1}\right) \times r \in \mathbf{C}_{\mathbf{B}}\left(\mathbf{S} \times \mathbb{R}_{+}^{I} \times \mathbb{R}_{+}^{I}\right)$. Then there exists a unique continuous function $R$ such that $R(s, K ; \alpha)=(T R)(s, K ; \alpha)$ for all $(s, K ; \alpha)$.

We now show that all our relevant $r(s, K ; \alpha)^{\prime} s$ are properly bounded and continuous when multiplied by $u^{\prime}\left(c_{1}(s, K ; \alpha)\right)$.

Lemma 5 For all $i$, suppose that $r(s, K ; \alpha)$ is one of the following functions:

(a) $c_{i}(s, K ; \alpha)$, 
(b) $Y_{i}(s, K ; \alpha)=\left(B_{i}(s) f\left(K_{i}\right)+(1-\delta) K_{i}-K_{i}^{\prime}(s, K ; \alpha)\right)$,

(c) $w_{i}(s, K ; \alpha)$,

(d) $d_{j}(s, K ; \alpha)$.

Then, in all these cases, $\left(u^{\prime} \circ c_{1}\right) \times r \in \mathbf{C}_{\mathbf{B}}\left(\mathbf{S} \times \mathbb{R}_{+}^{I} \times \mathbb{R}_{+}^{I}\right)$.

We are ready now to decentralize a Pareto optimal allocation as a RCE with zero initial transfers, conditional upon our assumptions about initial endowments. We consider two alternative complete market structures. From now on, we impose the consistency conditions (RCE 4) and thus we avoid writing policy functions depending on individual state variables.

\subsubsection{Complete Markets I: Only Short-Lived Assets are Traded}

Suppose initially that there is a full set of Arrow securities available. Below we show how to extend the analysis to a more general version of complete markets with an arbitrary payoff matrix of $S$ short-lived assets.

Consider the set of policy functions characterizing the solution of the recursive planner's problem (RPP). Given $\alpha$, define the stochastic discount factor as before, using (6). It follows from Lemmas 4 and 5 that the following functional equations have well-defined continuous solutions:

$$
\begin{aligned}
& V_{C}^{i}(s, K ; \alpha)=c_{i}(s, K ; \alpha)+\sum_{s^{\prime}} Q(s, K ; \alpha)\left(s^{\prime}\right) V_{C}^{i}\left(s^{\prime}, K^{\prime}(s, K ; \alpha)\right), \\
& V_{W}^{i}(s, K ; \alpha)= B_{i}(s) f\left(K_{i}\right)+(1-\delta) K_{i}-K_{i}^{\prime}(s, K ; \alpha) \\
&+\sum_{s^{\prime}} Q(s, K ; \alpha)\left(s^{\prime}\right) V_{W}^{i}\left(s^{\prime}, K^{\prime}(s, K ; \alpha)\right) .
\end{aligned}
$$

Note that these are the recursive versions of the value of consumption and net total wealth, respectively, given by (1) and (2).

Define transfers for agent $i$ by:

$$
\tau_{i}(s, K ; \alpha)=c_{i}(s, K ; \alpha)-\left[B_{i}(s) f\left(K_{i}\right)+(1-\delta) K_{i}-K_{i}^{\prime}(s, K ; \alpha)\right],
$$


and let "net asset holding" for each agent $i$ be defined by:

$$
\begin{aligned}
A_{i}(s, K ; \alpha) & =V_{C}^{i}(s, K ; \alpha)-V_{W}^{i}(s, K ; \alpha) \\
& =\tau_{i}(s, K ; \alpha)+\sum_{s^{\prime}} Q(s, K ; \alpha)\left(s^{\prime}\right) A_{i}\left(s^{\prime}, K^{\prime}(s, K ; \alpha)\right) .
\end{aligned}
$$

Note that feasibility implies that $\sum_{i} A_{i}(s, K ; \alpha)=0$ for all $(s, K ; \alpha)$. It follows from Lemmas 4 and 5 that there exists a unique continuous function $A_{i}$ : $\mathbf{S} \times \mathbb{R}_{+}^{I} \times \mathbb{R}_{+}^{I} \rightarrow \mathbb{R}$ for each $i$.

Before showing how to construct a RCE with a full set of Arrow securities using these $A_{i}$ 's, let us relate our framework to some previous results in the literature.

\section{The Endowment Economy}

Whenever $f\left(K_{i}\right)$ is constant for all $K_{i}$ and $\delta=0$, we get a version of the Lucas tree model with heterogeneous agents as described by JKS [2003]. Normalize $f\left(K_{i}^{0}\right)=1$ and let $\varepsilon_{i}(s)=B_{i}(s)+K_{i}^{0}$ for each $i$. Since the Second Welfare Theorem holds, any Pareto optimal allocation (parametrized by $\alpha$ ), $c_{i}(\alpha) \in \mathbb{R}^{S}$, can be decentralized as a RCE with transfers. Define transfers for agent $i$ by:

$$
\tau_{i}(s ; \alpha)=c_{i}(s ; \alpha)-\varepsilon_{i}(s),
$$

for each $s=1, \ldots, S$. In that case, the equilibrium Arrow security holdings are the solution to the $S$-dimensional system given by:

$$
a_{i}(s ; \alpha)=\tau_{i}(s ; \alpha)+\sum_{s^{\prime}} Q(s ; \alpha)\left(s^{\prime}\right) a_{i}\left(s^{\prime} ; \alpha\right),
$$

for $s=1, \ldots, S$.

It is easy to check that this system has a unique solution. Furthermore, continuity with respect to $\alpha$ implies that there exists $\alpha_{0}$ such that $a_{i}\left(s_{0} ; \alpha_{0}\right)=0$ for all $i$. Thus, the corresponding Pareto optimal allocation can be decentralized as a RCE without transfers as defined above. More importantly, and as properly pointed out by JKS [2003], note that (10) implies that the demands for next period's Arrow securities are independent of the unique aggregate state variable, $s$. That is, independently of 
the state $s$ today, agents construct a fixed equilibrium portfolio of Arrow securities. In fact, JKS [2003] show that this result is robust to include both more general heterogeneity across agents and trading in shares. This implies that equilibrium portfolios are in general constant after some initial rebalancing.

Therefore, the endowment economy version of the Lucas tree model with heterogeneous agents and dynamically complete markets cannot generate asset trading once one controls for the maturing of finite-lived assets. Thus, some other factors need to be considered. We show that the natural extension that includes production solves this apparent drawback.

Computing Arrow Security Holdings in the Production Economy

Let us go back to the economy with capital. Given $(s, K ; \alpha)$, note that $A_{i}(s, K ; \alpha)$ is uniquely determined by (9). This is an important aspect and it will be discussed in some more detail below.

Proposition 6 There exists a welfare weight $\alpha_{0}=\alpha\left(s_{0}, K_{0}\right)$ such that the corresponding Pareto optimal allocation can be decentralized as a RCE. The functions $A_{i}^{\prime} s$ defined by (9) can be used to construct the policy functions representing asset holdings in the following way:

$$
a_{i}^{\prime}(s, K, A)\left(s^{\prime}\right)=A_{i}\left(s^{\prime}, K^{\prime}(s, K) ; \alpha_{0}\right),
$$

where $A=A\left(s, K ; \alpha_{0}\right)$.

We find this result interesting for two reasons. First, it provides a simple existence proof of a RCE with heterogeneous households which can be easily extended to some other environments. For example, it is not hard to adapt the details to deal with irreversible investment and habit persistence in preferences. Secondly, it allows to construct an intuitive algorithm to compute equilibrium portfolios in production economies. Below we discuss the ability of this framework to generate asset trading volume. 
We now extend this result to a more general setup. Suppose that there are $S$ arbitrary short-lived assets. Let $h_{n}\left(s_{t}\right)$ be the payoff for security $n$ at $t$ and assume that the $S \times S$ matrix $\mathbf{h}=\left(h_{1}, \ldots, h_{S}\right)$ has full rank $S$ and thus markets are dynamically complete. Having computed $A_{i}(s, K)=A_{i}\left(s, K ; \alpha\left(s_{0}, K_{0}\right)\right)$ as before and given $K$, consider the following $S$-dimensional system and solve for $\left(a_{n}^{i}(K)\right)_{n=1}^{S}$ such that:

$$
A_{i}(s, K)=\sum_{n=1}^{S} h_{n}(s) a_{n}^{i}(K), \text { for } s=1, \ldots, S .
$$

Note that $A_{i}\left(s_{0}, K_{0}\right)=0$ for all $i$ does not necessarily imply that $a_{n}^{i}\left(K_{0}\right)=0$ for all $n$ and $i$. On the other hand, note that $\sum_{i} A_{i}(s, K)=0$ for all $(s, K)$ implies that $\sum_{i} a_{n}^{i}(K)=0$ for all $n$ and $K$ since $\mathbf{h}$ has full rank. Prices for these securities are given by the recursive formulation of the equation (5) above.

Corollary 7 The recursive Pareto optimal allocation corresponding to $\alpha_{0}$ can be decentralized as a RCE such that

$$
a_{i}^{\prime}(s, A, K)(n)=a_{n}^{i}\left(K^{\prime}(s, K)\right), \quad \text { for all } n=1, \ldots, S
$$

where $A=A\left(s, K ; \alpha_{0}\right)$.

Next we extend our results further to consider an alternative complete market structure where short-lived and long-lived assets coexist. This particular framework will allow us to study trading in stocks.

\subsubsection{Complete Markets II: Short and Long-Lived Assets Traded}

Suppose now that there are $S-I$ short-lived assets in zero net supply. Payoffs for security $n$ at $t$ are given by $h_{n}\left(s_{t}\right)$ as before and the $S \times(S-I)$ matrix $\left(h_{1}, \ldots, h_{S-I}\right)$ has rank $S-I$. Since agents can trade shares for all these $I$ firms, markets will be dynamically complete. ${ }^{11}$ Let $q_{n}\left(s^{t}\right)$ and $a_{i n}\left(s^{t}\right)$ be the price and holdings of the $n-t h$ asset, respectively. Whenever the subindex $n$ is not present, we refer to vectors and thus product means dot product.

\footnotetext{
${ }^{11}$ This is in generic sense. See JKS [2003] and references there for an additional discussion.
} 
We can write the budget constraint for this case as follows:

$h\left(s_{t}\right) a_{i}\left(s^{t-1}\right)+\sum_{j}\left[p_{j}\left(s^{t}\right)+d_{j}\left(s^{t}\right)\right] \theta_{i j}\left(s^{t-1}\right)=c_{i}\left(s^{t}\right)-w_{i}\left(s^{t}\right)+q\left(s^{t}\right) a_{i}\left(s^{t}\right)+\sum_{j} p_{j}\left(s^{t}\right) \theta_{i j}\left(s^{t}\right)$.

In a STCE, standard non-arbitrage conditions imply that the following condition will be satisfied for all $j$ and all $s^{t}$ :

$$
p_{j}\left(s^{t}\right)=\sum_{s^{\prime}} q\left(s^{t}\right)\left(s^{\prime}\right)\left[p_{j}\left(s^{t}, s^{\prime}\right)+d_{j}\left(s^{t}, s^{\prime}\right)\right]
$$

Note that, using and (11) and (5), it follows that for all $s^{t}$ :

$$
\begin{aligned}
q\left(s^{t}\right) a_{i}\left(s^{t}\right)+\sum_{j} p_{j}\left(s^{t}\right) \theta_{i j}\left(s^{t}\right) & =\sum_{n=1}^{N-I}\left(\sum_{s^{\prime}} q\left(s^{t}\right)\left(s^{\prime}\right) h_{n}\left(s^{\prime}\right)\right) a_{i n}\left(s^{t}\right) \\
& +\sum_{j}\left(\sum_{s^{\prime}} q\left(s^{t}\right)\left(s^{\prime}\right)\left[p_{j}\left(s^{t}, s^{\prime}\right)+d_{j}\left(s^{t}, s^{\prime}\right)\right]\right) \theta_{i j}\left(s^{t}\right) \\
& =\sum_{s^{\prime}} q\left(s^{t}\right)\left(s^{\prime}\right)\left[\sum_{n=1}^{N-I} h_{n}\left(s^{\prime}\right) a_{i n}\left(s^{t}\right)\right. \\
& \left.+\sum_{j}\left[p_{j}\left(s^{t}, s^{\prime}\right)+d_{j}\left(s^{t}, s^{\prime}\right)\right] \theta_{i j}\left(s^{t}\right)\right] .
\end{aligned}
$$

If we define financial wealth for agent $i$ at $s^{t}$ by:

$$
W_{i}\left(s^{t}\right)=h\left(s_{t}\right) a_{i}\left(s^{t-1}\right)+\sum_{j}\left[p_{j}\left(s^{t}\right)+d_{j}\left(s^{t}\right)\right] \theta_{i j}\left(s^{t-1}\right)
$$

then the budget constraint can be rewritten such that for all $s^{t}$ :

$$
W_{i}\left(s^{t}\right)=c_{i}\left(s^{t}\right)-w_{i}\left(s^{t}\right)+\sum_{s^{\prime}} q\left(s^{t}\right)\left(s^{\prime}\right) W_{i}\left(s^{t}, s^{\prime}\right) .
$$

The recursive formulation of this last equation is crucial to compute equilibrium portfolios with trading in long-lived assets. We proceed constructively as before to establish the existence of a RCE with this market structure. Using the policy functions from the recursive version of the planner's problem (RPP), get $V_{C}^{i}\left(s, K ; \alpha_{0}\right)$ using (7), where $\alpha_{0}$ is the welfare weight defined in Proposition 6. Also, define the value of human wealth for agent $i$ by:

$$
V_{\omega}^{i}\left(s, K ; \alpha_{0}\right)=w_{i}\left(s, K ; \alpha_{0}\right)+\sum_{s^{\prime}} Q\left(s, K ; \alpha_{0}\right)\left(s^{\prime}\right) V_{\omega}\left(s^{\prime}, K^{\prime}\left(s, K ; \alpha_{0}\right) ; \alpha_{0}\right) .
$$


It follows from Lemmas 4 and 5 that $V_{\omega}^{i}$ is a well-defined, unique continuous function. Note that $W_{i}\left(s, K ; \alpha_{0}\right)=V_{C}^{i}\left(s, K ; \alpha_{0}\right)-V_{\omega}^{i}\left(s, K ; \alpha_{0}\right)$.

Let

$$
\begin{aligned}
d_{j}\left(s, K ; \alpha_{0}\right) & =B_{j}(s) f\left(K_{j}\right)+(1-\delta) K_{j}-K_{j}^{\prime}\left(s, K ; \alpha_{0}\right)-w_{j}\left(s, K ; \alpha_{0}\right), \\
D_{j}\left(s, K ; \alpha_{0}\right) & =d_{j}\left(s, K ; \alpha_{0}\right)+\sum_{s^{\prime}} Q\left(s, K ; \alpha_{0}\right)\left(s^{\prime}\right) D_{j}\left(s^{\prime}, K_{j}^{\prime}\left(s, K ; \alpha_{0}\right) ; \alpha_{0}\right)
\end{aligned}
$$

Note that $D_{j}\left(s, K ; \alpha_{0}\right)$ is the recursive version of equation (4). Lemmas 4 and 5 imply that it is well-defined, unique and continuous.

Additionally, define the stock price for each $j$ as the solution to the following functional equation:

$$
p_{j}\left(s, K ; \alpha_{0}\right)=\sum_{s^{\prime}} Q\left(s, K ; \alpha_{0}\right)\left(s^{\prime}\right)\left[p_{j}\left(s^{\prime}, K^{\prime} ; \alpha_{0}\right)+d_{j}\left(s^{\prime}, K^{\prime} ; \alpha_{0}\right)\right],
$$

where $K^{\prime}=K^{\prime}\left(s, K ; \alpha_{0}\right)$. Lemmas 4 and 5 imply that there exists a unique continuous price system solving this functional equation for each $j$. The prices for the short-lived securities are given by:

$$
q_{n}\left(s, K ; \alpha_{0}\right)=\sum_{s^{\prime}} Q\left(s, K ; \alpha_{0}\right)\left(s^{\prime}\right) h_{n}\left(s^{\prime}\right)
$$

for all $n=1, \ldots, S-I$.

Finally, given $K$, solve for $\left[\left(a_{n}^{i}\left(K ; \alpha_{0}\right)\right)_{n=1}^{N-I},\left(\theta_{i}^{j}\left(K ; \alpha_{0}\right)\right)_{j=1}^{I}\right]$ satisfying:

$$
W_{i}\left(s, K ; \alpha_{0}\right)=\sum_{n=1}^{N-I} h_{n}(s) a_{i n}\left(K ; \alpha_{0}\right)+\sum_{j}\left[p_{j}(s, K ; \alpha)+d_{j}(s, K ; \alpha)\right] \theta_{i j}\left(K ; \alpha_{0}\right),
$$

for all $s \in\{1, \ldots, S\}$. Since the matrix $[\mathbf{h} \mathbf{p}+\mathbf{d}]$ has (generically) full rank $S$, the solution is well-defined and unique.

Proposition 8 The recursive Pareto optimal allocation corresponding to the welfare weight $\alpha_{0}$ established in Proposition 6 can be decentralized as a RCE with trading in long-lived assets. There, $(A, \Theta)$ is given by the solution of (14) and

$$
\begin{aligned}
a_{i}^{\prime}(s, A, \Theta, K)(n) & =a_{i n}\left(K^{\prime}(s, K) ; \alpha_{0}\right), \\
\theta_{i j}^{\prime}(s, A, \Theta, K) & =\theta_{i j}\left(K^{\prime}(s, K) ; \alpha_{0}\right) .
\end{aligned}
$$




\section{Discussion of Our Main Results}

Before illustrating our results computing some particular examples, the crucial aspects that differentiate this paper from the rest of the literature need to be emphasized here. As mentioned before, JKS [2003] is a particular case of our economy where equilibrium portfolios in both short-lived and long-lived assets are independent of the aggregate state of the economy. In that case, asset trading volume is restricted to the minimum. For instance, in the particular case where the number of states is the same as the number of trees, there is no trade at all after initial rebalancing.

Consider now the production economy and the dependence of portfolio policy functions with respect to the aggregate state (denoted by $(s, A, \Theta, K))$. First, notice that in fact the dependence with respect to $(A, \Theta)$ is irrelevant since given $(s, K)$ there is a unique equilibrium portfolio $(A, \Theta)(s, K)$ that can be sustained given by (14). Thus, the crucial dependence is with respect to $(s, K)$. More importantly, $\left(A^{\prime}, \Theta^{\prime}\right)$ is the unique vector of net positions in wealth that can be held in equilibrium next period, in every state of nature $s^{\prime}$. They depend upon $(s, K)$ because the physical state variable next period is determined today through $K^{\prime}(s, K)$. Other than that, equilibrium portfolios do not depend upon $(s, K)$.

Now, to further understand the intuition for our results, consider an economy populated by two agents trading a full set of Arrow securities. Suppose that there are two different aggregate states $(s, K)$ and $(\widetilde{s}, \widetilde{K})$ such that $K_{1}^{\prime}(s, K)>K_{1}^{\prime}(\widetilde{s}, \widetilde{K})$ and $K_{2}^{\prime}(s, K)<K_{2}^{\prime}(\widetilde{s}, \widetilde{K}) .{ }^{12}$ Given $\alpha_{0}$, next period agent 1 is relatively richer if the current state today is $(s, K)$ than if it is $(\widetilde{s}, \widetilde{K})$. Therefore, the transfers the planner would need to make tomorrow from agent 2 to agent 1 in order to make the corresponding consumption bundle affordable is smaller if the current state is $(s, K)$ than if the

\footnotetext{
${ }^{12}$ The reader might wonder if states like these are ever reached. The examples computed below show that the answer is in fact positive. Moreover, it can be formally shown that these states are reached with positive probability if firms are heterogeneous. Roughly speaking, the argument goes as follows. The joint process $\left(s_{t}, K\left(s^{t-1}\right)\right)$ follows a stationary Markov process (see Stokey, Lucas and Prescott [1989], Theorem 9.13). It can additionally be shown that the monotone mixing property is satisfied. Consequently, it follows that such states are reached with positive probability (see Stokey, Lucas and Prescott [1989], p. 381). Details are left to the reader.
} 
current state is $(\widetilde{s}, \widetilde{K})$. This implies that $A_{1}\left(s^{\prime}, K^{\prime}(s, K)\right)<A_{1}\left(s^{\prime}, K^{\prime}(\widetilde{s}, \widetilde{K})\right)$ for all $s^{\prime}$. The implications for the decentralized version are then the following. In state $(\widetilde{s}, \widetilde{K})$ agent 1 decreases next-period output through $K_{1}^{\prime}(\widetilde{s}, \widetilde{K})$ across all future states $s^{\prime}$ (when compared with the state $(s, K)$ ). To transfer resources contingent on $s^{\prime}$, he uses Arrow securities where $a^{\prime}(s, K, A)\left(s^{\prime}\right)=A_{1}\left(s^{\prime}, K_{1}^{\prime}(s, K)\right)$ (remember that $A=A(s, K))$. For any $s^{\prime}$, this amount depends on the technological possibilities of generating output in the next period, which is determined by $K_{1}^{\prime}(s, K)$. Thus, differently from the endowment economy, an agent will have the option to transfer resources using both securities and capital. Other things equal and for each state $s^{\prime}$ next period, a higher level of individual capital next period will make an agent trade less today in the asset markets in order to transfer less consumption from today to tomorrow using these assets. And this is the case because he is already transferring relatively more through this higher level of capital next period.

Note that at any current state $(s, K)$, the degree of heterogeneity across agents is represented by the distribution of capital $K$ while next period it will be represented by $K^{\prime}(s, K)$. This is the reason why heterogeneity across agents changes as time and uncertainty unfold. The same reasoning explains changing equilibrium portfolios in a framework with trading in both short-lived assets and stocks. In particular, it explains why equilibrium stock holdings are not kept fixed in general.

\section{Equilibrium Portfolios with CRRA Preferences}

In this section we assume that preferences are restricted to the case where

$$
u\left(c_{i}\right)=\frac{\left(c_{i}\right)^{1-\sigma}}{1-\sigma}
$$

for each $i \in \Upsilon$ where $\sigma>0$ is the coefficient of relative risk aversion. ${ }^{13}$ Thus, given a vector $\alpha=\left(\alpha_{1}, \ldots, \alpha_{I}\right)$, first order conditions for the recursive Pareto problem (RPP)

\footnotetext{
${ }^{13}$ In the preceding sections, we assumed that utility functions were bounded from below. In our examples, if $\sigma \geq 1$ this assumption is not satisfied. However, all our results can be replicated for these cases using the techniques explained in Alvarez and Stokey [1998].
} 
imply that any solution will satisfy, for each $i$ :

$$
c_{i}(s, K ; \alpha)=\frac{\left(\alpha_{i}\right)^{1 / \sigma}}{\sum_{j=1}^{I}\left(\alpha_{j}\right)^{1 / \sigma}} C(s, K),
$$

where $C(s, K)$ is aggregate consumption. Since the solution is immune to affine linear transformations of preferences ${ }^{14}$, the planner's problem given any $\alpha$ is equivalent to solving:

$$
V(s, K ; \alpha)=\max _{\left(C, K^{\prime}\right) \geq 0}\left\{\frac{C^{1-\sigma}}{1-\sigma}+\beta \sum_{s} \pi\left(s, s^{\prime}\right) V\left(s^{\prime}, K^{\prime} ; \alpha\right)\right\}
$$

subject to

$$
C+\sum_{i}\left[K_{i}^{\prime}-(1-\delta) K_{i}\right]=\sum_{i} B_{i}(s) f\left(K_{i}\right)
$$

Given the solution $\left(C(s, K), K^{\prime}(s, K)\right)$ to problem $\left(\mathrm{P}^{*}\right)$, individual consumptions are obtained using (16). Very importantly, note that this means that both the capital accumulation path and the implicit prices are independent of the wealth distribution. This is a fundamental feature of the particular representation of preferences we assume in (15). We normalize $\sum_{j=1}^{I}\left(\alpha_{j}\right)^{1 / \sigma}=1$.

Using the solution to problem $\left(\mathrm{P}^{*}\right)$, define for each $j$ and each $s^{\prime}$ :

$$
\begin{aligned}
d_{j}(s, K) & =B_{j}(s) f\left(K_{j}\right)+(1-\delta) K_{j}-K_{j}^{\prime}(s, K)-w^{j}(s, K), \\
Q(s, K)\left(s^{\prime}\right) & =\beta \pi\left(s, s^{\prime}\right) \frac{u^{\prime}\left(C\left(s^{\prime}, K^{\prime}(s, K)\right)\right)}{u^{\prime}(C(s, K))}, \\
p_{j}(s, K) & =\sum_{s^{\prime}} Q(s, K)\left(s^{\prime}\right)\left[p_{j}\left(s^{\prime}, K^{\prime}(s, K)\right)+d_{j}\left(s^{\prime}, K^{\prime}(s, K)\right)\right] .
\end{aligned}
$$

Compute first the value of aggregate consumption as the solution of the following functional equation:

$$
V_{C_{A}}(s, K)=C(s, K)+\sum_{s^{\prime}} Q(s, K)\left(s^{\prime}\right) V_{C_{A}}\left(s^{\prime}, K^{\prime}(s, K)\right) .
$$

Lemmas 4 and 5 imply that there exists a unique continuous solution $V_{C_{A}}$.

\footnotetext{
${ }^{14}$ Here, $\sum_{i} \alpha_{i} \frac{\left(c_{i}\left(s^{t}\right)\right)^{1-\sigma}}{1-\sigma}$ reduces to $\frac{\left(C\left(s^{t}\right)\right)^{1-\sigma}}{1-\sigma}\left(\sum_{i}\left(\alpha_{i}\right)^{1 / \sigma}\right)^{\sigma}$ for each $s^{t}$.
} 
Note that for each $i$

$$
\begin{aligned}
V_{W}^{i}(s, K)= & B_{i}(s) f\left(K_{i}\right)+(1-\delta) K_{i}-K_{i}^{\prime}(s, K) \\
& +\sum_{s^{\prime}} Q(s, K)\left(s^{\prime}\right) V_{W}^{i}\left(s^{\prime}, K^{\prime}(s, K)\right),
\end{aligned}
$$

is independent of $\alpha$. Also, since $w_{i}(s, K)=B_{i}(s) F_{2}\left(K_{i}, 1\right)$ we have that

$$
V_{\omega}^{i}(s, K)=w_{i}(s, K)+\sum_{s^{\prime}} Q(s, K)\left(s^{\prime}\right) V_{\omega}^{i}\left(s^{\prime}, K^{\prime}(s, K)\right)
$$

is independent of $\alpha$ as well. Note also that it can be verified that for each agent $i$ we have:

$$
V_{C}^{i}(s, K ; \alpha)=\left(\alpha_{i}\right)^{1 / \sigma} V_{C_{A}}(s, K)
$$

for all $\alpha$. To obtain this result, substitute this candidate for $V_{C}^{i}$ in (7). Using (17) and the uniqueness of the $V_{C}^{i}$ show that (18) holds. Therefore, it follows that for all $i:$

$$
\begin{aligned}
A^{i}(s, K ; \alpha) & =V_{C}^{i}(s, K ; \alpha)-V_{W}^{i}(s, K) \\
& =\left(\alpha_{i}\right)^{1 / \sigma} V_{C_{A}}(s, K)-V_{W}^{i}(s, K) .
\end{aligned}
$$

Given some initial $\left(s_{0}, K_{0}\right)$, we are ready to compute $\alpha\left(s_{0}, K_{0}\right)$ by simply letting:

$$
\alpha_{i}\left(s_{0}, K_{0}\right)=\left(\frac{V_{W}^{i}\left(s_{0}, K_{0}\right)}{V_{C_{A}}\left(s_{0}, K_{0}\right)}\right)^{\sigma}
$$

for $i=1, \ldots,(I-1)$. Put $\alpha_{I}\left(s_{0}, K_{0}\right)=\left(1-\sum_{j=1}^{I-1}\left(\alpha_{j}\left(s_{0}, K_{0}\right)\right)^{1 / \sigma}\right)^{\sigma}$. As shown in Proposition 8, since for each $i$ :

$$
V_{W}^{i}(s, K)=\left[p_{i}(s, K)+d_{i}(s, K)\right]+V_{\omega}^{i}(s, K),
$$

it is possible to check that in fact:

$$
W_{i}\left(s_{0}, K_{0} ; \alpha\left(s_{0}, K_{0}\right)\right)=p_{i}\left(s_{0}, K_{0}\right)+d_{i}\left(s_{0}, K_{0}\right),
$$

as our assumptions on initial distribution of wealth require for economies where both short-lived and long-lived assets are traded. ${ }^{15}$

\footnotetext{
${ }^{15}$ See the proof of Proposition 8 in the Appendix.
} 
The examples below will quantitatively illustrate our main findings. In both examples, we let the number of Markov states $S=5$ and the number of agents and technologies $I=2$. Using the CRRA specification given by (15), we set $\sigma=2$ for both agents, and the discount factor $\beta=0.95$. Both technologies are assumed to be CobbDouglas, where $F\left(K_{i}, L_{i}\right)=K_{i}^{0.33} L_{i}^{0.67}, i=1,2$. The depreciation rate is assigned a value of $\delta=0.1$. Less extreme assumptions about limited labor substitutability can be considered if, for example, $F\left(K_{i}, L_{1}, L_{2}\right)=K_{i}^{\alpha}\left(a_{1}^{i}\left(L_{1}\right)^{\rho}+a_{2}^{i}\left(L_{2}\right)^{\rho}\right)^{\frac{1-\alpha}{\rho}}$ with $a_{1}^{i}+a_{2}^{i}=1$. Here, $0<\rho \leq 1$ and $1 /(1-\rho)$ is the elasticity of substitution between $L_{1}$ and $L_{2}$. In our particular framework, we simply impose $a_{i}^{i}=1$ for each technology $i$.

The mapping from states to total factor productivities for the individual technologies, $B_{i}(s)$, is as follows:

$$
\begin{array}{cccccc} 
& s=1 & s=2 & s=3 & s=4 & s=5 \\
B_{1}(s) & 1.00 & 1.05 & 0.95 & 1.05 & 0.95 \\
B_{2}(s) & 1.00 & 1.05 & 1.05 & 0.95 & 0.95
\end{array} .
$$

Note that this formulation purposely allows for both aggregate and "redistributive" shocks to production possibilities. In particular, shocks $\{1,2,5\}$ will represent an economy in "normal times", an expansion and a recession, respectively. On the other hand, shocks $\{3,4\}$ have a redistributive component.

The Markov transition matrix is given by:

$$
\prod=\left[\begin{array}{lllll}
0.6 & 0.1 & 0.1 & 0.1 & 0.1 \\
0.1 & 0.6 & 0.1 & 0.1 & 0.1 \\
0.1 & 0.1 & 0.6 & 0.1 & 0.1 \\
0.1 & 0.1 & 0.1 & 0.6 & 0.1 \\
0.1 & 0.1 & 0.1 & 0.1 & 0.6
\end{array}\right]
$$

We assume that the initial state of the Markov process is $s_{0}=1$, and the initial value for both types of capital stock is set to the steady state value computed for this specific $s_{0}$. Very importantly, note that these initial conditions, coupled with our assumptions about $\left(B_{1}, B_{2}\right)$ and $\Pi$, imply that agents are ex-ante identical. As already mentioned, heterogeneity across agents appears as time and uncertainty unfold. 


\subsection{Example 1: Arrow Securities}

In the first example we assume that the set of securities that can be sequentially traded consists of a full set of Arrow securities.

The solution proceeds by taking the steps outlined above, i.e., by solving the planner's problem to get aggregate consumption and investment, solving the functional equations $V_{C_{A}}$ and $V_{W}^{i}$, and finding the welfare weights implied by the initial values, according to equation (19).

Finally, for each $i$, let:

$$
A^{i}(s, K)=\left(\alpha_{i}\left(s_{0}, K_{0}\right)\right)^{1 / \sigma} V_{C_{A}}(s, K)-V_{W}^{i}(s, K),
$$

and construct equilibrium portfolios of Arrow securities according to Proposition 6 .

Figures 1-3 below present the results for this example. Figure 1 shows the evolution of consumption, capital, asset holdings and asset prices for a realization of a time series for 100 periods. Figures 2 and 3 show histograms of the stationary distributions of Arrow security holdings and trading volume respectively. Trading volume is simply defined as the number of individual securities traded every period. For security $s^{\prime}$, this is represented by the absolute value of agent 1's security holdings in $s^{\prime}$, that is $\left|a_{1}^{\prime}(s, A, K)\left(s^{\prime}\right)\right|$. As suggested above, the asset holdings of these securities fluctuate. In particular, they evolve conditional upon the evolution of capital across firms. Note that the symmetry of payoffs and transition probabilities is reflected in the symmetry of trading volumes. For the holdings the same pattern obtains, just modified by the general principle that agents go short in the Arrow security that pays off in states when their own type is relatively more productive and tend to hold the Arrow security that pays a return when their relative productivity is low. 

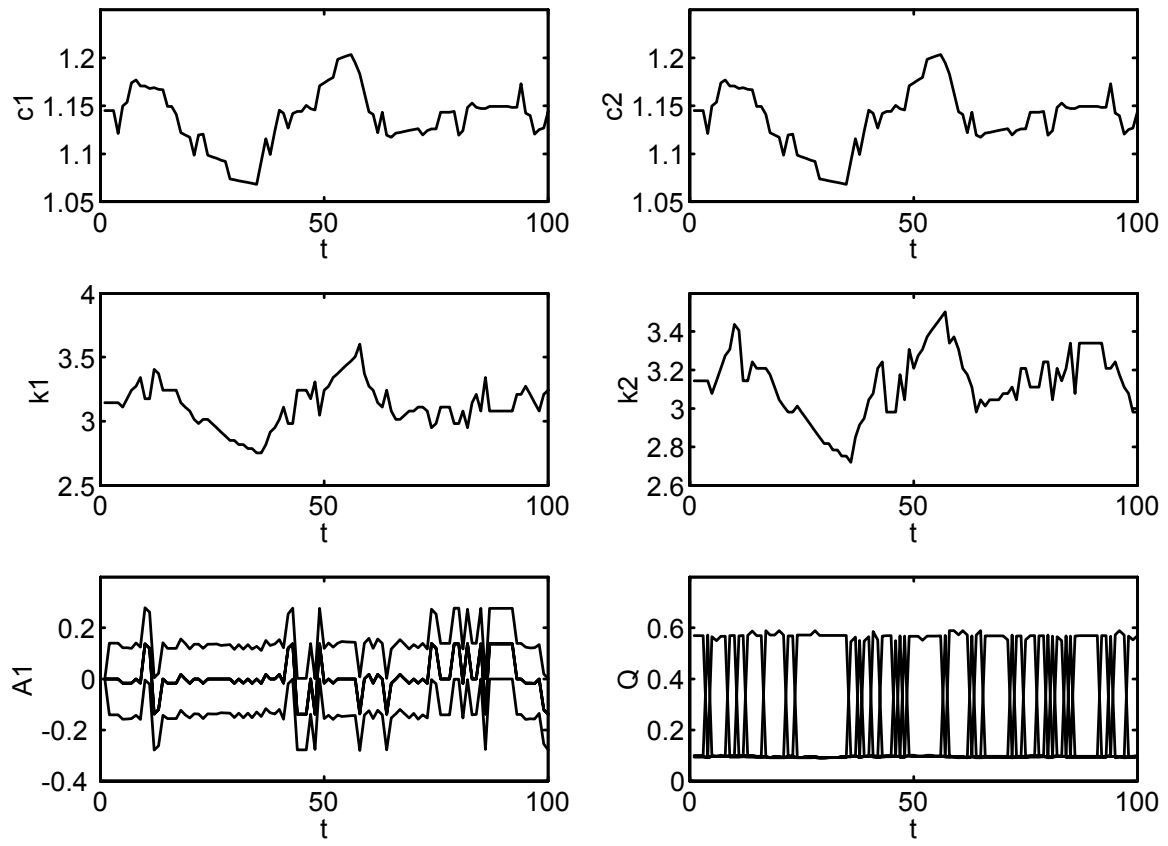

Figure 1: Time Series Solution, $\mathrm{T}=100$.
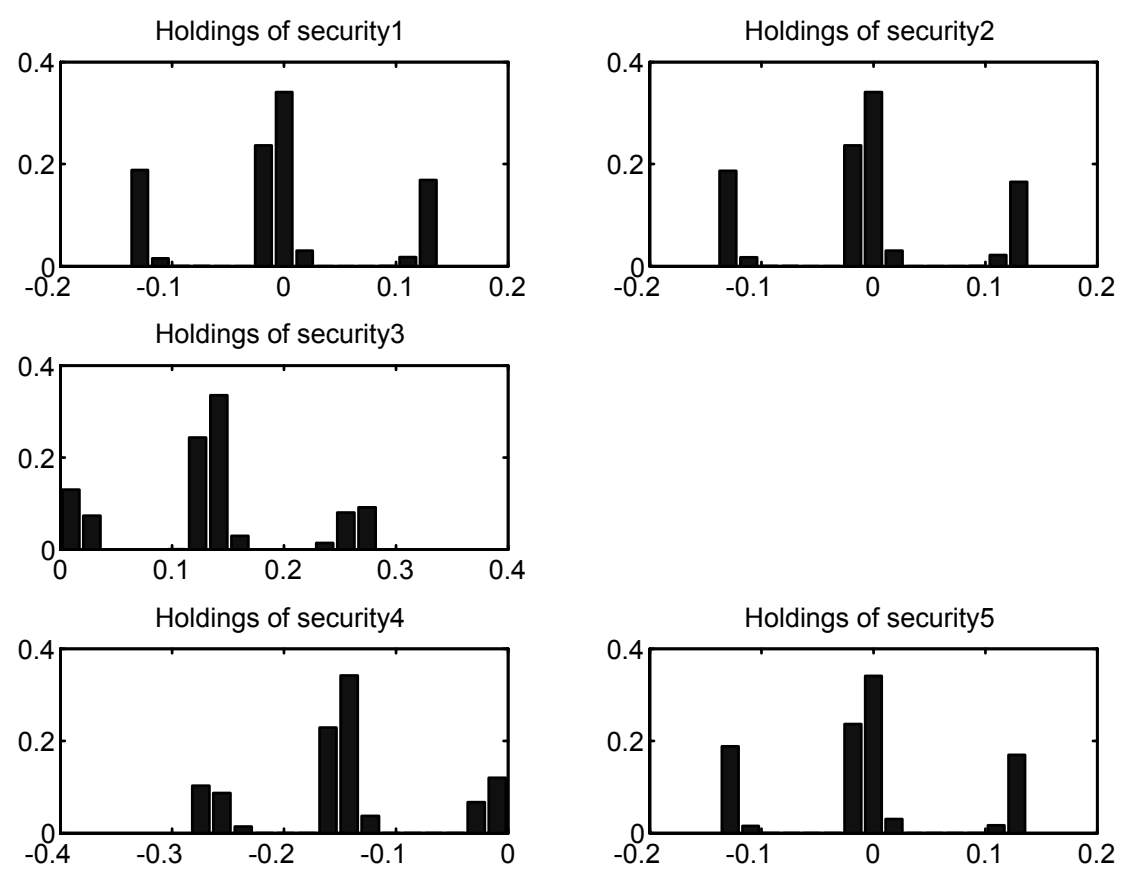

Figure 2: Stationary Distributions of Arrow Security Holdings 

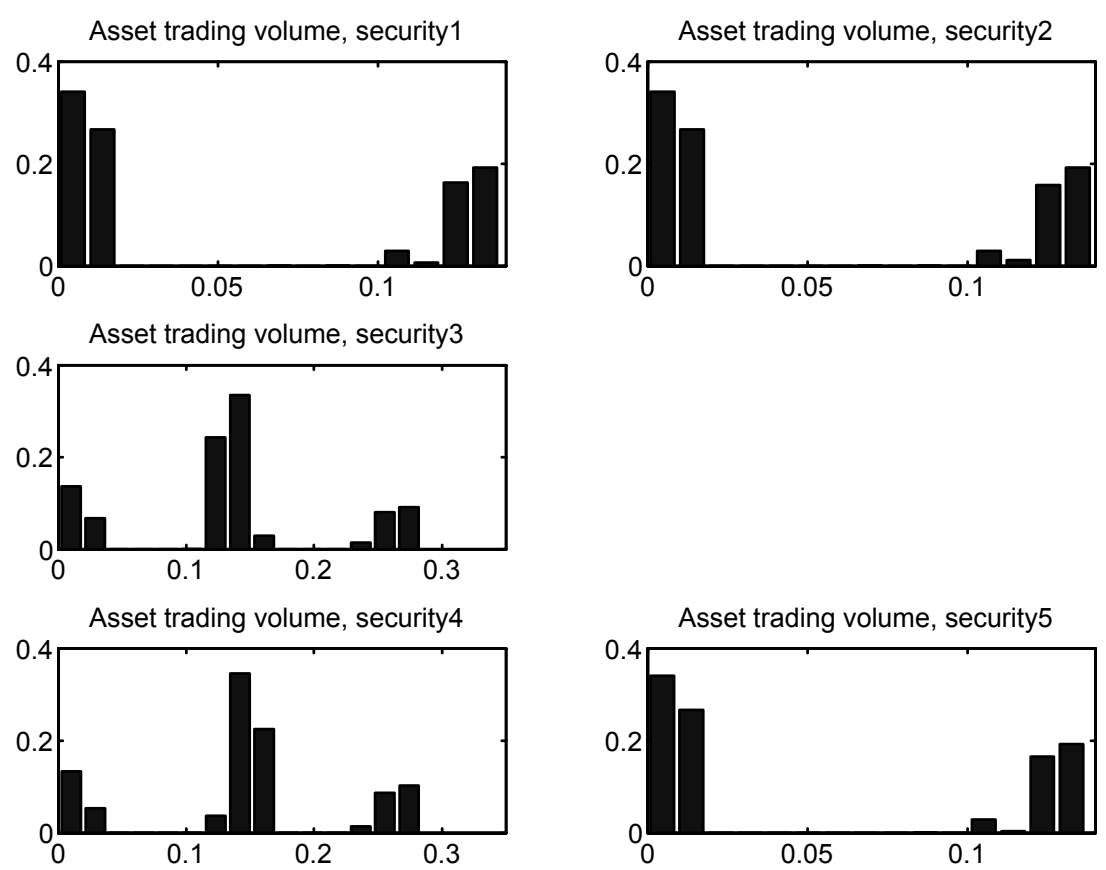

Figure 3: Stationary Distributions of Asset Trading Volumes.

\subsection{Example 2: Trading Short and Long Lived Securities}

In this example, we assume that the securities that can be traded in the economy are different. Here, there are 2 long-lived assets. They represent shares in the individual firms where the number of outstanding shares is normalized to unity. Given that $S=5$, we assume that there are $5-2=3$ short-lived assets and consequently markets are dynamically complete. The short-lived assets are in zero net supply and have the following payoff structure:

$$
h_{1}=\left(\begin{array}{l}
1 \\
0 \\
0 \\
0 \\
0
\end{array}\right), h_{2}=\left(\begin{array}{l}
0 \\
1 \\
0 \\
0 \\
0
\end{array}\right), h_{3}=\left(\begin{array}{l}
0 \\
0 \\
0 \\
0 \\
1
\end{array}\right) .
$$

Recall, from the specification of $B_{i}(s)$, that $s=1,2,5$ are the states that map into equal total factor productivities for both types. For each of these states there is a security which pays one unit if and only if that state occurs.

Since we assume that markets are dynamically complete in both examples, the 
allocation of consumption and capital is the same. Therefore, we can rely on the solution of the planner's problem from the previous example since the welfare weights to decentralize this Pareto optimal allocation as a RCE with this alternative market structure is the same as in the previous example (Proposition 8). The value of aggregate consumption, $V_{C_{A}}$, is then the same as well. On the other hand, functional equations need to be solved to compute the value of human wealth, $V_{\omega}^{i}$, and also the equilibrium prices of shares, $p_{j}$. We then have all the ingredients required to calculate equilibrium portfolio holdings.

For each $i$, let:

$$
W_{i}(s, K)=\left(\alpha_{i}\left(s_{0}, K_{0}\right)\right)^{1 / \sigma} V_{C_{A}}(s, K)-V_{\omega}^{i}(s, K)
$$

and construct equilibrium portfolios as in Proposition 8. The following set of Figures illustrates the results for this example. Like in the previous example, trading volume is simply defined as the number of individual securities traded every period. For firm $j$ stock, this is represented by the absolute value of the difference in agent 1's stock holdings of firm $j$, that is $\left|\theta_{1 j}^{\prime}-\theta_{1 j}\right|$.

The fifth panel in Figure 4 shows that agents tend to hold short positions in their own firms' stocks and go long in the other agent's firm. Intuitively, this allows them to hedge risk against idiosyncratic income shocks, which they are facing by being productive just in the firm of their own type. The picture of share prices shows that there is some common movement but also some changes of relative stock prices over time. The holdings of short-lived securities seem low, especially when compared to the amount of stocks in the portfolio. These observations are clear from the stationary distribution of asset holdings in Figure 5. Figure 6 demonstrates the peculiar symmetry contained in the model's assumptions. The payoff-structure of the short-lived assets is neutral with respect to types, meaning that it does not provide returns when redistributive shocks to individual production occur. Payoffs in those states can only come from individual share holdings. 

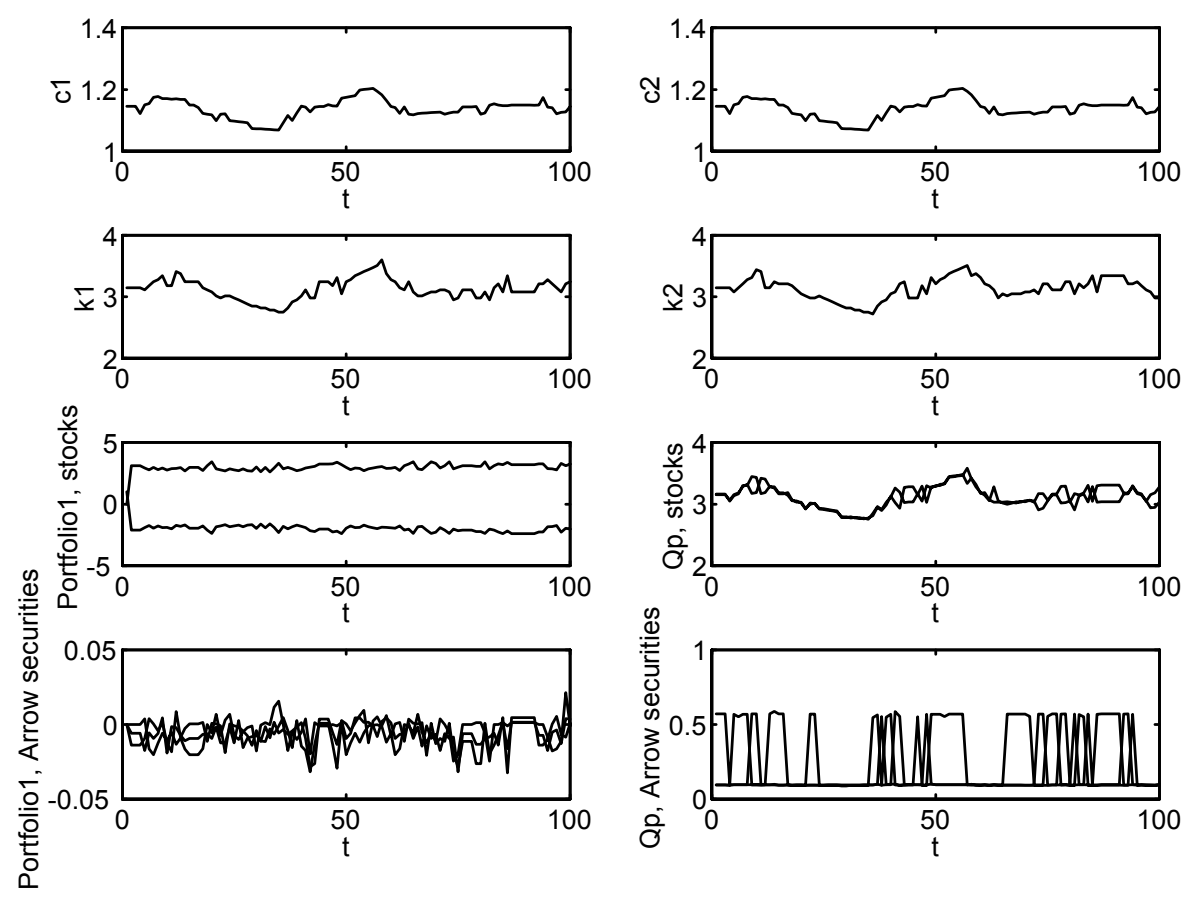

Figure 4: Time Series Solution, $\mathrm{T}=100$.
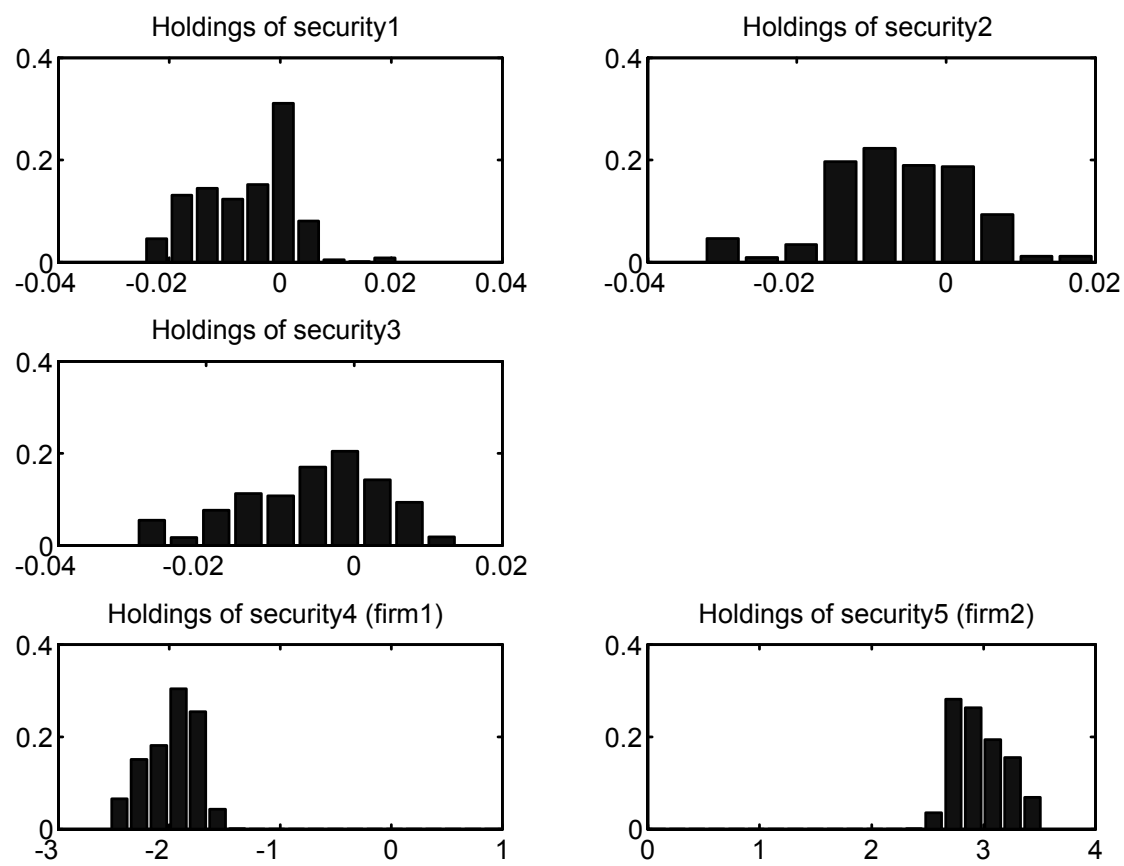

Figure 5: Stationary Distribuition of Asset Holdings. 

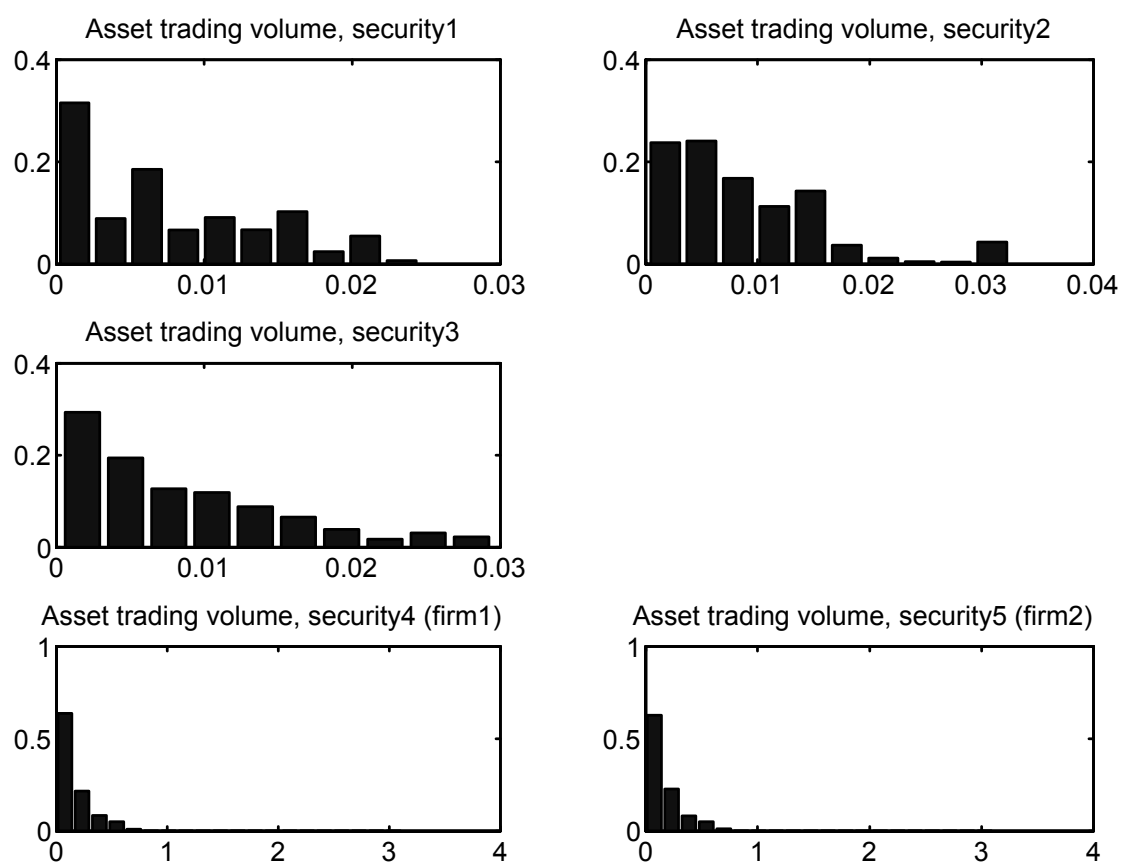

Figure 6: Stationary Distributions of Asset and Stock Trading Volumes.

\section{Conclusion}

The endowment version of the Lucas tree model with heterogeneous agents and dynamically complete markets has performed poorly to explain asset trading volume, as explained by Judd, Kubler and Schmedders [2003]. This paper extends that environment in a natural way to study asset trading volume in production economies with heterogenous agents and alternative dynamically complete market structures. We show that this environment can generate a nontrivial amount of trading in both short-lived and long-lived assets. The main difference is that in our framework agents are able to manipulate not only portfolios but also the stock of capital to transfer consumption across time and states of nature. For a given state of nature next period, different distributions of next period's capital will make agents choose different equilibrium portfolios to transfer resources either to or from that state. The stock of capital itself is used to transfer consumption from today to tomorrow. Depending upon the value of the marginal productivity of capital next period, in some cases an 
agent chooses to transfer more consumption to all the states next period using capital (high value of marginal productivity) trading relatively less assets. In other cases (low value of marginal productivity), he transfers less consumption accumulating less and trades more assets paying next period. This alternative instrument to transfer consumption across time is naturally missed in a pure exchange economy.

The crucial aspect in our model is that at a given period, heterogeneity across agents is determined by the distribution of capital across firms. And this is the case because we assume that labor of different types are imperfect substitutes. Therefore, the evolution of the distribution of capital explains why agents' heterogeneity changes as time and uncertainty unfold. This naturally leads to changing equilibrium portfolios.

An important aspect illustrated by the examples above is that it is possible to shut down initial heterogeneity making agents ex-ante identical. Very importantly, they show that this framework can generate changing ex-post heterogeneity and consequently one can still get nontrivial asset trading volume. It is still an open question if the model can generate trading volume when the driving forces generating these changes in heterogeneity in our framework are assumed away (namely, ex-post differences in marginal productivity of capital across firms and different equilibrium wages). In that case, to generate changes in heterogeneity one should only rely on the persistence of unequal initial levels of wealth. This has been left for future research.

The model presented here can be easily extended in several directions to allow for more realistic assumptions. As already mentioned, it is easy to have agents with arbitrary initial distributions of endowments and property rights. More importantly, it is possible to adjust the details in the characterization of the planner's problem to deal with adjustment costs and habit persistency in preferences. The impact of these two additional assumptions coupled together (and even the necessity of them) have been studied in the literature. In particular, they have been successful to help 
explaining both key asset-returns facts and business-cycle facts, outperforming the standard RBC model and the Lucas tree model (see Boldrin et al. [2001] and Jermann [1998]). It seems natural then to study the impact of this more ambitious framework on asset trading volume. This would be a fairly straightforward task within the framework presented here.

Other potential application of our model and its extensions would be in the international RBC literature. For example, one could pin down welfare weights to match the actual distribution of wealth across countries. Thus, the model can be considered a benchmark to understand asset trading across different countries. 


\section{Appendix}

Notice first that necessary and sufficient conditions characterizing the planner's solution are given by: ${ }^{16}$

$$
\begin{gathered}
u^{\prime}\left(c_{1}(s, K ; \alpha)\right)=\beta \sum_{s^{\prime}} \pi\left(s, s^{\prime}\right) u^{\prime}\left(c_{1}\left(s^{\prime}, K^{\prime}(s, K ; \alpha)\right) \times\right. \\
{\left[B_{i}\left(s^{\prime}\right) f^{\prime}\left(K_{i}^{\prime}(s, K ; \alpha)\right)+(1-\delta)\right],} \\
\alpha_{i} u^{\prime}\left(c_{i}(s, K ; \alpha)\right)=\alpha_{h} u^{\prime}\left(c_{h}(s, K ; \alpha)\right), \quad \text { for } \quad \text { all } \quad i, h \in \Upsilon, \\
\sum_{i \in \Upsilon} c_{i}(s, K ; \alpha)+\sum_{i \in \Upsilon}\left[K_{i}^{\prime}(s, K ; \alpha)-(1-\delta) K_{i}\right]=\sum_{i \in \Upsilon} B_{i}(s) f\left(K_{i}\right) .
\end{gathered}
$$

This already uses the Benveniste-Scheinkman condition which implies that for all $i$ :

$$
\frac{\partial V(s, K ; \alpha)}{\partial K_{i}}=\alpha_{1} u^{\prime}\left(c_{1}(s, K ; \alpha)\right)\left[B_{i}(s) f^{\prime}\left(K_{i}\right)+(1-\delta)\right] .
$$

On the other hand, using the consistency requirements (RCE 4), the following conditions fully characterize a RCE (see footnote (16)):

$$
\begin{gathered}
1=\sum_{s^{\prime}} Q(s, A, \Theta, K)\left(s^{\prime}\right)\left[B_{j}\left(s^{\prime}\right) f^{\prime}\left(K_{j}^{\prime}(s, A, \Theta, K)\right)+(1-\delta)\right], \\
w_{j}(s, A, \Theta, K)=B_{j}(s) F_{2}\left(K_{j}, 1\right) \\
Q(s, A, \Theta, K)\left(s^{\prime}\right)=\beta \pi\left(s, s^{\prime}\right) \frac{u^{\prime}\left(c_{i}\left(s^{\prime}, A^{\prime}, \Theta^{\prime}, K^{\prime}\right)\right)}{u^{\prime}\left(c_{i}(s, A, \Theta, K)\right)} \\
p_{j}(s, A, \Theta, K)=\sum_{s^{\prime}} Q(s, A, \Theta, K)\left(s^{\prime}\right)\left[p_{j}\left(s^{\prime}, A^{\prime}, \Theta^{\prime}, K^{\prime}\right)+d_{j}\left(s^{\prime}, A^{\prime}, \Theta^{\prime}, K^{\prime}\right)\right], \\
c_{i}(s, A, \Theta, K)+\sum_{j} p_{j}(s, A, \Theta, K) \theta_{i j}^{\prime}(s, A, \Theta, K) \\
+\sum_{s^{\prime}} Q(s, A, \Theta, K)\left(s^{\prime}\right) a_{i}^{\prime}\left(s^{\prime}\right)(s, A, \Theta, K) \\
=w_{i}(s, A, \Theta, K)+A_{i}+\sum_{j}\left[p_{j}(s, A, \Theta, K)+d_{j}(s, A, \Theta, K)\right] \theta_{i j}, \\
\sum_{i \in \Upsilon} c_{i}(s, A, \Theta, K)-\sum_{j \in \Upsilon}\left(K_{j}^{\prime}(s, A, \Theta, K)-(1-\delta) K_{j}\right)=\sum_{j \in \Upsilon} B_{j}(s) f\left(K_{j}\right),
\end{gathered}
$$

\footnotetext{
${ }^{16}$ Note that under our assumptions the transversality condition is immediately satisfied. This condition is not only sufficient but also necessary in this framework.
} 


$$
\begin{gathered}
\sum_{i \in \Upsilon} A_{i}^{\prime}(s, A, \Theta, K)\left(s^{\prime}\right)=0, \quad \text { for all } s^{\prime} \\
\sum_{i \in \Upsilon} \Theta_{i j}^{\prime}(s, A, \Theta, K)=1, \quad \text { for all } j .
\end{gathered}
$$

It is important to mention that to apply the Second Welfare Theorem, except for (27), (29) and (30), the conditions characterizing a RCE are satisfied either by construction or by definition.

Proof of Lemma 4. Let $\mathbf{C}_{\mathbf{B}}\left(\mathbf{S} \times \mathbb{R}_{+}^{I} \times \mathbb{R}_{+}^{I}\right)$ be the set of continuous and bounded functions mapping $\mathbf{S} \times \mathbb{R}_{+}^{I} \times \mathbb{R}_{+}^{I}$ into the real numbers. Consider the alternative operator $\widetilde{T}$ :

$$
(\widetilde{T} M)(s, K ; \alpha)=r(s, K ; \alpha) u^{\prime}\left(c_{1}(s, K ; \alpha)\right)+\sum_{s^{\prime}} \beta \pi\left(s, s^{\prime}\right) M\left(s^{\prime}, K^{\prime}(s, K ; \alpha) ; \alpha\right) .
$$

Step 1. First we check that $\widetilde{T}: \mathbf{C}_{\mathbf{B}}\left(\mathbf{S} \times \mathbb{R}_{+}^{I} \times \mathbb{R}_{+}^{I}\right) \rightarrow \mathbf{C}_{\mathbf{B}}\left(\mathbf{S} \times \mathbb{R}_{+}^{I} \times \mathbb{R}_{+}^{I}\right)$.

Suppose that $M \in \mathbf{C}_{\mathbf{B}}\left(\mathbf{S} \times \mathbb{R}_{+}^{I} \times \mathbb{R}_{+}^{I}\right)$. By assumption, $r(s, K ; \alpha) u^{\prime}\left(c_{1}(s, K ; \alpha)\right)$ is continuous for all $(s, K ; \alpha)$ and there exists some $0<\mathbf{B}<\infty$ such that $\left|r(s, K ; \alpha) u^{\prime}\left(c_{1}(s, K ; \alpha)\right)\right|<$ $\mathbf{B}$ for all $(s, K ; \boldsymbol{\alpha})$. It is clear then that $(\widetilde{T} M) \in \mathbf{C}_{\mathbf{B}}\left(\mathbf{S} \times \mathbb{R}_{+}^{I} \times \mathbb{R}_{+}^{I}\right)$.

Step 2. Now we show that $\widetilde{T}$ is a contraction mapping.

We check Blackwell's sufficient conditions. We start with discounting. Consider any $a>0$. Note that:

$$
\begin{aligned}
(\widetilde{T}(M+a))(s, K ; \alpha) & =r(s, K ; \alpha) u^{\prime}\left(c_{1}(s, K ; \alpha)\right)+\sum_{s^{\prime}} \beta \pi\left(s, s^{\prime}\right)\left(M\left(s^{\prime}, K^{\prime}(s, K) ; \alpha\right)+a\right) \\
& \leq r(s, K ; \alpha) u^{\prime}\left(c_{1}(s, K ; \alpha)\right)+\sum_{s^{\prime}} \beta \pi\left(s, s^{\prime}\right) M\left(s^{\prime}, K^{\prime}(s, K) ; \alpha\right)+\beta a \\
& =(\widetilde{T} R)(s, K ; \alpha)+\beta a .
\end{aligned}
$$

Monotonicity is obvious: if $M(s, K ; \alpha) \geq D(s, K ; \alpha)$ for all $(s, K ; \alpha)$, it is immediate that $(\widetilde{T} M)(s, K ; \alpha) \geq(\widetilde{T} D)(s, K ; \alpha)$ for $\operatorname{all}(s, K ; \alpha)$.

By the contraction mapping theorem we can conclude that $\widetilde{T}$ is a contraction with a unique solution $M \in \mathbf{C}_{\mathbf{B}}\left(\mathbf{S} \times \mathbb{R}_{+}^{I} \times \mathbb{R}_{+}^{I}\right)$. Therefore, to conclude the proof, define:

$$
R(s, K ; \alpha)=M(s, K ; \alpha)) / u^{\prime}\left(c_{1}(s, K ; \alpha)\right)
$$


It can be checked immediately that $R$ is a continuous function which is the unique fixed point of the operator $T$ as required.

Proof of Lemma 5. First notice that since policy functions are continuous, $r(s, K ; \alpha) u^{\prime}\left(c_{1}(s, K ; \alpha)\right)$ is continuous for all these cases. We now check that it is also bounded. Let $\bar{Y}=\max _{(s)} \sum_{i} B_{i}(s) f(\bar{K})+(1-\delta) \bar{K}$. To simplify the exposition, let us assume that there exists some $\gamma \in(0,1)$ such that $\gamma f(K) \leq f^{\prime}(K) K$ for all $K$.

(a) Note first that from $(21)$, it follows that $u^{\prime}\left(c_{1}(s, K ; \alpha)\right)=\frac{\alpha_{i}}{\alpha_{1}} u^{\prime}\left(c_{i}(s, K ; \alpha)\right)$ for all $i$. Since $u$ is concave, it follows that for all $c>0$ :

$$
0 \leq c u^{\prime}(c) \leq u(c) \leq u(\bar{Y})
$$

(b) Since the planner's value function is concave, strictly increasing and differentiable, it follows that:

$$
0 \leq \nabla_{k} V(s, K) \cdot K \leq V(s, K)-V(s, 0) \leq \max _{s} V(s, \bar{K}) \equiv \bar{V}
$$

Also, the envelope condition implies that,

$$
\alpha_{1} u^{\prime}\left(c_{1}(s, K ; \alpha)\right)\left(\sum_{i \in \Upsilon}\left[B_{i}(s) f^{\prime}\left(K_{i}\right) K_{i}+(1-\delta) K_{i}\right]\right)=\nabla_{k} V(s, K) \cdot K \leq \bar{V}
$$

Assumptions about production functions let us conclude that for all $(s, K ; \alpha)$ :

$$
0 \leq \alpha_{1} u^{\prime}\left(c_{1}(s, K ; \alpha)\right)\left[\gamma B_{i}(s) f\left(K_{i}\right)+(1-\delta) K_{i}\right] \leq \bar{V}
$$

Also, since $w_{i}(s, K ; \alpha)=(1-\gamma) B_{i}(s) f\left(K_{i}\right)$, we can immediately conclude that $u^{\prime}\left(c_{1}(s, K ; \alpha)\right) w_{i}(s, K ; \alpha)$ is uniformly bounded. Moreover, note that:

$$
u^{\prime}\left(c_{1}(s, K ; \alpha)\right)\left(\sum_{i \in \Upsilon} Y_{i}(s, K ; \alpha)\right)=u^{\prime}\left(c_{1}(s, K ; \alpha)\right)\left(\sum_{i \in \Upsilon} c_{i}(s, K ; \alpha)\right),
$$

is also uniformly bounded. Note here that:

$$
u^{\prime}\left(c_{1}(s, K ; \alpha)\right) Y_{i}(s, K ; \alpha) \leq u^{\prime}\left(c_{1}(s, K ; \alpha)\right)\left[B_{i}(s) f\left(K_{i}\right)+(1-\delta) K_{i}\right]
$$

is bounded from above. This implies that $u^{\prime}\left(c_{1}(s, K ; \alpha)\right) Y_{i}(s, K ; \alpha)$ is also uniformly bounded from below since otherwise it follows from (31) that there exists some $h$ 
such that $u^{\prime}\left(c_{1}(s, K ; \alpha)\right) Y_{h}(s, K ; \alpha)$ is unbounded from above. But this case has been already ruled out.

Finally note that $\left|d_{j}(s, K ; \alpha)\right|=\left|Y_{i}(s, K ; \alpha)-w_{i}(s, K ; \alpha)\right| \leq\left|Y_{i}(s, K ; \alpha)\right|+w_{i}(s, K ; \alpha)$ and then $u^{\prime}\left(c_{1}(s, K ; \alpha)\right)\left|d_{j}(s, K ; \alpha)\right|$ is uniformly bounded as well.

Proof of Proposition 6. Note first that if $\alpha_{i}=0$ then $c_{i}(s, K ; \alpha)=0$ and consequently $V_{C}^{i}(s, K ; \alpha)=0$ for all $(s, K)$ in this case. This implies that $A_{i}(s, K ; \alpha)=-V_{W}^{i}(s, K ; \alpha)$. By definition and given that the planner chooses to operate the technology $i$ optimally, it is easy to show that $V_{W}^{i}(s, K ; \alpha)>0$ for all $(s, K)$ with $K>0 .{ }^{17}$ Now we will proceed in two steps.

Step 1. There exists some $\alpha_{0}=\alpha\left(s_{0}, K_{0}\right)$ such that $A_{i}\left(s_{0}, K_{0} ; \alpha\left(s_{0}, K_{0}\right)\right)=0$.

It can be verified that $A_{i}^{\prime} s$ are homogeneous of degree 0 in $\alpha$. Therefore, we can normalize and consider welfare weights in the $I-1$ dimensional unit simplex, $\Delta^{I-1}$. Define the vector-valued function $g$ as follows:

$$
g^{i}(\alpha)=\frac{\max \left[\alpha^{i}-A^{i}\left(s_{0}, K_{0} ; \alpha\right), 0\right]}{\sum_{i} \max \left[\alpha^{i}-A^{i}\left(s_{0}, K_{0} ; \alpha\right), 0\right]},
$$

for each $i$. Note that $H(\alpha)=\sum_{i} \max \left[\alpha^{i}-A^{i}\left(s_{0}, K_{0} ; \alpha\right), 0\right]$ is positive for all $\alpha \in$ $\Delta^{I-1} \cdot{ }^{18}$ Also, $g^{i}(\alpha) \in[0,1]$ and $\sum_{i} g^{i}(\alpha)=1$ for all $\alpha$. Thus, $g$ is a continuous function mapping $\Delta^{I-1}$ into itself. By Brower's fixed point theorem, there exists some $\alpha_{0}=\alpha\left(s_{0}, K_{0}\right)$ such that $\alpha_{0}=g\left(\alpha_{0}\right)$. Suppose now that $\alpha_{0}^{i}=0$ for some $i$. This implies that $-A^{i}\left(s_{0}, K_{0} ; \alpha_{0}\right) \leq 0$. But we have already discussed that $-A^{i}\left(s_{0}, K_{0} ; \alpha_{0}\right)=V_{W}\left(s_{0}, K_{0} ; \alpha_{0}\right)>0$ if $\alpha_{0}^{i}=g^{i}(\alpha)=0$ and then this would lead to a contradiction. Hence, $\alpha_{0}^{i}>0$ for all $i$ and this implies that $\alpha^{i}-A^{i}\left(s_{0}, K_{0} ; \alpha_{0}\right)>0$

\footnotetext{
${ }^{17}$ The intuition for this can be grasped as follows. $V_{W}$ is the "value" of operating the firm $i$, using the planner's shadow prices. The planner might choose not to operate this technology at all getting a non-negative value since $K_{i} \geq 0$. But under our assumptions the planner's solution is interior and unique. This implies that this value $V_{W}$ has to be strictly greater than this alternative plan rendering a non-negative value. Additional details are available upon request.

${ }^{18}$ That is,

$$
H(\alpha)=\sum_{i} \max \left[\alpha^{i}-A^{i}\left(s_{0}, K_{0} ; \alpha\right), 0\right] \geq \sum_{i} \alpha^{i}-\sum_{i} A^{i}\left(s_{0}, K_{0} ; \alpha\right)=1
$$

for all $\alpha \in \Delta^{I-1}$.
} 
for all $i$. Consequently,

$$
H\left(\alpha_{0}\right) \alpha_{0}^{i}=\max \left[\alpha_{0}^{i}-A^{i}\left(s_{0}, K_{0} ; \alpha\right), 0\right]=\alpha_{0}^{i}-A^{i}\left(s_{0}, K_{0} ; \alpha_{0}\right) .
$$

Note that this implies that $H\left(\alpha_{0}\right) \sum_{i} \alpha_{0}^{i}=\sum_{i} \alpha_{0}^{i}-\sum_{i} A^{i}\left(s_{0}, K_{0} ; \alpha_{0}\right)=1=H\left(\alpha_{0}\right)$. Therefore, $\alpha_{0}^{i}=\alpha_{0}^{i}-A^{i}\left(s_{0}, K_{0} ; \alpha_{0}\right)$ which immediately shows that $A^{i}\left(s_{0}, K_{0} ; \alpha_{0}\right)=0$ for all $i$.

Step 2. Let $A=A\left(s, K ; \alpha_{0}\right)$ and define for each $i$ :

$$
\begin{gathered}
\left.a_{i}^{\prime}(s, K, A)\left(s^{\prime}\right)=A_{i}\left(s^{\prime}, K^{\prime}(s, K) ; \alpha_{0}\right)\right), \\
Q(s, A, K)\left(s^{\prime}\right)=\beta \pi\left(s, s^{\prime}\right) \frac{u^{\prime}\left(c_{1}\left(s^{\prime}, K^{\prime}(s, K) ; \alpha_{0}\right)\right)}{u^{\prime}\left(c_{1}\left(s, K ; \alpha_{0}\right)\right)} .
\end{gathered}
$$

It is important to remember that $A_{i}(s, K)$ equals the unique present discounted value of future over-expenditures that can be afforded at the state $(s, K)$. Consider the conditions characterizing a RCE, assuming away trading in stocks. All these conditions are satisfied by construction ${ }^{19}$. Note that:

$$
\begin{aligned}
A_{i}= & {\left[c_{i}(s, A, K)+K_{i}^{\prime}(s, A, K)-k_{i}(1-\delta)-B_{i}(s) f\left(K_{i}\right)\right] } \\
& +\sum_{s^{\prime}} Q(s, A, K)\left(s^{\prime}\right) a_{i}^{\prime}(s, A, K)\left(s^{\prime}\right),
\end{aligned}
$$

where $c_{i}(s, A, K)=c_{i}\left(s, K ; \alpha_{0}\right)$ and $K_{i}^{\prime}(s, A, K)=K_{i}^{\prime}\left(s, A ; \alpha_{0}\right)$ for all $i$. In fact, given $(s, K)$, the unique levels of asset holdings that can be sustained in a RCE are fully characterized by $A(s, K)$. Therefore, the solution of the planner's problem with welfare weights $\alpha_{0}$ coupled with (32) and (33) constitutes a RCE.

Proof of Proposition 8. The construction of the RCE is identical to that detailed in Proposition 6. Details are left to the reader except for one step. We show that given $\alpha_{0}=\alpha\left(s_{0}, K_{0}\right)$, it follows that for each $i$ :

$$
W_{i}\left(s_{0}, K_{0} ; \alpha_{0}\right)=p_{i}\left(s_{0}, K_{0} ; \alpha_{0}\right)+d_{i}\left(s_{0}, K_{0} ; \alpha_{0}\right),
$$

\footnotetext{
${ }^{19}$ Note that market clearing conditions in asset markets are satisfied also by construction as discussed in the text.
} 
and therefore there is no need for additional transfers at $\left(s_{0}, K_{0}\right)$ given the ownership structure assumed. To see this, note that for each $i$ :

$$
\begin{aligned}
V_{W}^{i}\left(s, K ; \alpha_{0}\right)= & B_{i}(s) f\left(K_{i}\right)+(1-\delta) K_{i}-K_{i}^{\prime}\left(s, K ; \alpha_{0}\right) \\
& +\sum_{s^{\prime}} Q\left(s, K ; \alpha_{0}\right)\left(s^{\prime}\right) V_{W}^{i}\left(s^{\prime}, K^{\prime}\left(s, K ; \alpha_{0}\right) ; \alpha_{0}\right) \\
= & d_{i}\left(s, K ; \alpha_{0}\right)+w_{i}\left(s, K ; \alpha_{0}\right)+\sum_{s^{\prime}} Q\left(s, K ; \alpha_{0}\right)\left(s^{\prime}\right) V_{W}^{i}\left(s^{\prime}, K^{\prime}\left(s, K ; \alpha_{0}\right) ; \alpha_{0}\right) .
\end{aligned}
$$

Then, we can actually write:

$$
\begin{aligned}
V_{W}^{i}\left(s, K ; \alpha_{0}\right)= & d_{i}\left(s, K ; \alpha_{0}\right)+w_{i}\left(s, K ; \alpha_{0}\right) \\
& +\sum_{s^{\prime}} Q\left(s, K ; \alpha_{0}\right)\left(s^{\prime}\right)\left[D_{i}\left(s^{\prime}, K^{\prime}\left(s, K ; \alpha_{0}\right) ; \alpha_{0}\right)+V_{\omega}^{i}\left(s^{\prime}, K^{\prime}\left(s, K ; \alpha_{0}\right) ; \alpha_{0}\right)\right] .
\end{aligned}
$$

where $D_{i}$ is defined by (13). Since the stock prices are uniquely determined, it can be verified that for all $i$ :

$$
p_{i}\left(s, K ; \alpha_{0}\right)=\sum_{s^{\prime}} Q\left(s, K ; \alpha_{0}\right)\left(s^{\prime}\right) D_{i}\left(s^{\prime}, K^{\prime}\left(s, K ; \alpha_{0}\right) ; \alpha_{0}\right)
$$

and, therefore,

$$
V_{W}^{i}\left(s, K ; \alpha_{0}\right)=\left[p_{i}\left(s, K ; \alpha_{0}\right)+d_{i}\left(s, K ; \alpha_{0}\right)\right]+V_{\omega}^{i}\left(s, K ; \alpha_{0}\right) .
$$

Since $A_{i}\left(s, K ; \alpha_{0}\right)=V_{C}^{i}\left(s, K ; \alpha_{0}\right)-V_{W}^{i}\left(s, K ; \alpha_{o}\right)$ and $W_{i}\left(s, K ; \alpha_{0}\right)=V_{C}^{i}\left(s, K ; \alpha_{0}\right)-$ $V_{\omega}^{i}\left(s, K ; \alpha_{0}\right)$, this immediately implies that

$$
W_{i}\left(s_{0}, K_{0} ; \alpha_{0}\right)=p_{i}\left(s_{0}, K_{0} ; \alpha_{0}\right)+d_{i}\left(s_{0}, K_{0} ; \alpha_{0}\right),
$$

as desired. Finally, notice that adding up (14) and using (34) it follows that market clearing conditions for assets and stocks markets ((29) and (30) respectively) are satisfied since $\sum_{i} A_{i}\left(s, K ; \alpha_{0}\right)=0$ and the matrix $[\mathbf{h} \mathbf{p}+\mathbf{d}]$ has (generically) full rank $S$. 


\section{References}

[1] Alvarez, F. And Stokey, n. [1998]: "Dynamic Programming with Homogenous Functions", Journal of Economic Theory, 82, 167-189.

[2] Boldrin, M., Christiano, L. And fisher, J. [2001]: "Habit Persistence, Asset Returns, and the Business Cycle", American Economic Review, 91 (1), 149-166.

[3] Brock, w. [1982]: "Asset Prices in a Production Economy", in John J. McCall, ed., The Economics of Information and Uncertainty (The University of Chicago Press, Chicago, IL).

[4] Brock, W. And Lebaron, B. [1996]: "A Dynamic Structural Model for Stock Return Volatility and Trading Volume", The Review of Economics and Statistics, 78 (1), 94-110.

[5] Constantinides, G. And Duffie, D. [1996]: "Asset Pricing with Heterogeneous Consumers", Journal of Political Economy, vol. 104 (2), 219-240.

[6] ESPino, E. [2005]: “On Ramsey's Conjecture: Efficient Allocations in the Neoclassical Growth Model with Private Information", forthcoming, Journal of Economic Theory (Working Paper Version: IHS Economics Series Nr. 154).

[7] espino, E. And hintermaier, t. [2005]: "Occasionally Binding Collateral Constraints, Asset Returns and the Business Cycle", Working Paper, IHS.

[8] Jermann, u. [1998]: "Asset Pricing in Production Economies", Journal of Monetary Economics, vol. 41, 257-75.

[9] JUdD, K., KUbler, F. ANd Schmedders, K. [2003]: "Asset Trading Volume in Infinite-Horizon Economies with Dynamically Complete Markets and Heterogeneous Agents", Journal of Finance, 63, 2203-2217.

[10] Lettau, M. [2003]: "Inspecting the Mechanism: Closed-Form Solutions for Asset Prices in BBC Models", The Economic Journal, 113 (July), 550-575. 
[11] Ljungqvist, L. And Sargent, t. [2004]: Recursive Macroeconomic Theory. Second Edition. Cambridge, Mass.: The MIT Press.

[12] LUCAS, R. E. JR. [1978]: "Asset Prices in an Exchange Economy", Econometrica, 46, 1429-1445.

[13] LO, A. And WAng, J. [2000]: "Trading Volume: Definitions, Data Analysis, and Implications of Portfolio Theory", Review of Financial Studies, 13 (2), 257-300.

[14] NEGishi, T. [1960]: "Welfare Economics and the Existence of an Equilibrium for a Competitive Economy", Metroeconomica, 7, 92-97.

[15] PRESCOtT, E.C. AND MeHRA, R. [1980]: "Recursive Competitive Equilibrium: The Case of Homogeneous Households," Econometrica, 48, 1980, 1365-1379.

[16] Stokey, N., LuCAs, R. E. JR. And PRescott, E.C. [1989]: Recursive Methods in Economic Dynamics, Cambridge, MA: Harvard University Press. 